\title{
An Evaluation of Neurotoxicity Following Fluoride Exposure from Gestational Through Adult Ages in Long-Evans Hooded Rats
}

\author{
Christopher A. McPherson ${ }^{1} \cdot$ Guozhu Zhang ${ }^{2} \cdot$ Richard Gilliam $^{1} \cdot$ Sukhdev S. Brar ${ }^{3} \cdot$ Ralph Wilson $^{3} \cdot$ Amy Brix $^{4}$. \\ Catherine Picut ${ }^{5} \cdot$ G. Jean Harry ${ }^{1}$ (I)
}

Received: 30 October 2017 / Revised: 11 January 2018 / Accepted: 12 January 2018 / Published online: 5 February 2018

(C) The Author(s) 2018. This article is an open access publication

\begin{abstract}
At elevated levels, fluoride $\left(\mathrm{F}^{-}\right)$exposure has been associated with adverse human health effects. In rodents, $\mathrm{F}^{-}$exposure has been reported to induce deficits in motor performance and learning and memory. In this study, we examined Long-Evans hooded male rats maintained on a standard diet $\left(20.5 \mathrm{ppm} \mathrm{F}^{-}\right)$or a low $\mathrm{F}^{-} \operatorname{diet}\left(3.24 \mathrm{ppm} \mathrm{F}^{-}\right)$with drinking water exposure to 0,10 , or

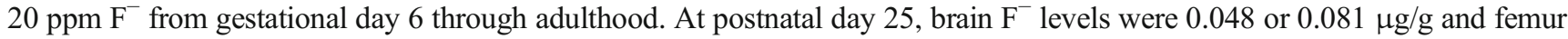
235 or $379.8 \mu \mathrm{g} / \mathrm{g}$ for 10 and $20 \mathrm{ppm} \mathrm{F}^{-}$, respectively. Levels increase with age and in adults, levels for plasma were 0.036 or $0.025 \mu \mathrm{g} / \mathrm{ml}$; for the brain 0.266 or $0.850 \mu \mathrm{g} / \mathrm{g}$; and for the femur, 681.2 or $993.4 \mu \mathrm{g} / \mathrm{g}$. At these exposure levels, we observed no exposure-related differences in motor, sensory, or learning and memory performance on running wheel, open-field activity, light/ dark place preference, elevated plus maze, pre-pulse startle inhibition, passive avoidance, hot-plate latency, Morris water maze acquisition, probe test, reversal learning, and Y-maze. Serum triiodothyronine (T3), thyroxine (T4), and thyroid stimulating hormone (TSH) levels were not altered as a function of 10 or $20 \mathrm{ppm} \mathrm{F}^{-}$in the drinking water. No exposure-related pathology was observed in the heart, liver, kidney, testes, seminal vesicles, or epididymides. Mild inflammation in the prostate gland was observed at $20 \mathrm{ppm} \mathrm{F}^{-}$. No evidence of neuronal death or glial activation was observed in the hippocampus at $20 \mathrm{ppm} \mathrm{F}^{-}$.
\end{abstract}

Keywords Fluoride $\cdot$ Learning and memory $\cdot$ Avoidance $\cdot$ Activity $\cdot$ Neurodevelopment

Electronic supplementary material The online version of this article (https://doi.org/10.1007/s12640-018-9870-x) contains supplementary material, which is available to authorized users.

\section{G. Jean Harry}

harry@niehs.nih.gov

1 Neurotoxicology Group, National Toxicology Program Laboratory, National Institute of Environmental Health Sciences, Mail Drop C1-04, P.O. Box 12233, Research Triangle Park, NC 27709, USA

2 Social \& Scientific Systems, Inc, Durham, NC 27703, USA

3 Cellular \& Molecular Pathology Branch, Division of the National Toxicology Program, NIEHS, Research Tringle Park, NC 27709, USA

4 Experimental Pathology Laboratories, Research Triangle Park, NC, USA

5 Charles River Laboratories, Inc, Durham, NC, USA

\section{Introduction}

Many US public water systems add fluoride to finished water as a preventive against dental caries with a US Public Health Service recommended water fluoridation level of $0.7 \mathrm{ppm}$. Under the Safe Drinking Water Act, the US Environmental Protection Agency (EPA) set the current enforceable upper concentration limit at $4 \mathrm{ppm}$ in drinking water derived from sources with naturally high fluoride to prevent skeletal fluorosis. The secondary drinking water standard is $2 \mathrm{ppm}$ and systems distributing water around this level are required to notify the affected public (US EPA 2013). The EPA proposed a reference dose of $0.08 \mathrm{mg} / \mathrm{kg} /$ day for protection against dental fluorosis and skeletal fractures (US EPA 2010). This is equivalent to a daily dose of $\sim 5.6 \mathrm{mg}$ for an adult and $~$ $1.6 \mathrm{mg}$ for a child. Studies examining associations between drinking water fluoride and neurological deficits or dysfunction have generated concerns for human exposure. Studies of 
sample populations in fluoride-endemic areas suggested an inverse association between high levels of naturally occurring fluoride in water and intelligence quotient; however, the level of confidence in these conclusions is low (Choi et al. 2012; Sutton et al. 2015). A recent study by Bashash et al. (2017) reported an association between prenatal maternal urine fluoride levels $(0.90 \pm 0.35 \mathrm{ppm})$ and performance of offspring (6-12 years of age) on tests of intelligence.

The question of potential neurological effects from fluoride exposures in experimental rodent models was examined in a recent systematic review of behavior (NTP (National Toxicology Program) 2016). Translation of findings from these studies to human exposures is often difficult because of the high levels of fluoride $\left(\mathrm{F}^{-},>100 \mathrm{ppm}\right)$ administered or routes of exposure not representative of drinking water. The majority of rat studies have focused on exposure to adult males with only a limited number examining developmental exposure (Wang et al. 2004; Niu et al. 2009; El-lethey et al. 2010; Banji et al. 2013; Jiang et al. 2014b; Wei et al. 2014). At drinking water concentrations of $\geq 100 \mathrm{ppm} \mathrm{F}^{-}$, various studies suggested performance deficits in rats on learning and memory tasks (Basha et al. 2011; Basha and Sujitha 2012; Jiang et al. 2014a; Zhu et al. 2017). However, many of these findings occurred in the presence of potential motor dysfunction or general toxicity (Bera et al. 2007; Basha and Sujitha 2012; Balaji et al. 2015); thus, diminishing confidence in any conclusion of learning deficits. Studies examining $\mathrm{F}^{-}$exposures $\leq$ $100 \mathrm{ppm}$ present an inconsistent pattern of neurobehavioral effects. A number of studies reported effects on motor or learning performance in rats at drinking water concentrations of $\sim 2$ to $50 \mathrm{ppm} \mathrm{F}^{-}$(Bera et al. 2007; Gao et al. 2008; Liu et al. 2009; El-lethey et al. 2010; Jiang et al. 2014b; Wang et al. 2004; Wu et al. 2006; Wei et al. 2014; Bartos et al. 2015; Dong et al. 2015a). Many of these studies had limitations in experimental design and often utilized latency measures of learning that were dependent on a motor response (NTP 2016). Rather than examining improvement in performance with training (acquisition), many studies relied on a single assessment of learning and a single latency measure at the end of training (Gao et al. 2008, 2009a, b; Jiang et al. 2014b; Wei et al. 2014; Dong et al. 2015a), not taking into consideration the initial latency differences. In studies that reported acquisition data, longer latencies were often observed; yet, performance improved with training (Gui et al. 2010; Basha et al. 2011; Basha and Sujitha 2012; Zhu et al. 2017). These findings suggested a need to discriminate between effects on motor and learning in assessing $\mathrm{F}^{-}$ neurotoxicity.

The current study was designed to address issues identified in the NTP systematic review (NTP 2016) of determining low to moderate levels of evidence for effects of $\mathrm{F}^{-}$exposure on learning and memory and to address the paucity of quality studies conducted at exposure levels near the recommended level for community water fluoridation in the USA.
Equivalent human daily water intakes of $1.74 \mathrm{mg}$ F/day for an adult or $0.63-1.23 \mathrm{mg}$ /day for 1 to 14 years of age (US EPA 2010) have been approximated in rodents using drinking water concentrations of 7 to $9 \mathrm{ppm} \mathrm{F}^{-}$(NTP 2016). In the current study, the top dose of $20 \mathrm{ppm} \mathrm{F}^{-}$was selected based upon the US Environmental Protection Agency's Maximum Contaminant Level of $4 \mathrm{ppm}$ and the conventional wisdom that a 5 -fold increase in dose is required to achieve comparable human serum levels (Dunipace et al. 1995; NRC 2006). We examined the effects of $\mathrm{F}^{-}$exposure initiated during prenatal development by replicating and refining testing paradigms, assessing multiple sensory and motor modalities, and examining learning and memory across different test paradigms. Additional effects reported for $\mathrm{F}^{-}$exposure that may influence behavior were examined (i.e., the thyroid hormone levels, kidney, liver, reproductive system histopathology, and neuronal and glia morphology in the hippocampus) to obtain a better understanding of observed effects.

\section{Materials and Methods}

\section{Animals and Dosing}

Timed-pregnant Long-Evans hooded rats (Charles River Laboratory, Raleigh, NC) were obtained (four shipments over 6 months) on gestational day (GD) 4 and individually housed in ventilated cages (Techniplast, West Chester, PA) with autoclaved, hardwood bedding (PJ Murphy, Montville, NY) within a semi-barrier room (40-60\% humidity; 12-h light/dark cycle, $6: 00-18: 00 ; 20-24^{\circ} \mathrm{C}$ ). Dams were randomly assigned to exposure group. Two drinking water control groups were maintained on reverse osmosis drinking water $\left(\mathrm{RO}-\mathrm{H}_{2} \mathrm{O}\right)$. One group (G1) was maintained on a standard rodent chow (Teklad 2918; Envigo, Madison, WI) and the second (G2) was maintained on a low-fluoride chow (Teklad Custom Diet TD.160173). To examine the effect of fluoride in the drinking water while controlling for dietary fluoride, rats were exposed to the low-fluoride chow and water supplemented with either $10 \mathrm{ppm} \mathrm{F}^{-}$(G3) or $20 \mathrm{ppm} \mathrm{F}^{-}$(G4). Dosing solutions were prepared fresh weekly with sodium fluoride (NaF; lot no. X0044851; 99.9\%; Materion, Milwaukee, WI). Fluoride levels in drinking water were confirmed $\left[\mathrm{RO}-\mathrm{H}_{2} \mathrm{O},<\right.$ $0.2 \mathrm{ppm} ; 10$ and $20 \mathrm{ppm} \mathrm{F}^{-}$within $\leq 5 \%$ of target] (analytical method: EPA 300.0; Pace Analytical, Huntersville, NC). The Teklad 2918 diet contained $20.5 \mathrm{ppm} \mathrm{F}^{-}$and the TD.160173 custom diet contained $3.24 \mathrm{ppm} \mathrm{F}^{-}$(Official Methods of Analysis Methods 944.08 and 978.03; AOAC International, Gaithersburg, MD; Covance, Madison, WI). Food and water were available ad libitum. Exposure to the dams began on GD6 and continued throughout lactation. Pups were allowed free access to drinking water, beginning consumption around PND14, and continued on the same level of exposure after 
weaning until study termination. All animal procedures were conducted in accordance with protocols approved by the NIEHS Animal Care and Use Committee within AAALAC approved animal facilities.

The day of birth, postnatal day (PND) 0 , occurred within $12 \mathrm{~h}$ with similar pup numbers across groups. On PND4, pups within each group were cross-fostered to establish litters of ten pups (six male and four female pups). Male pups were toetattooed (BD PrecisionGlide 27G needle) and randomly assigned to four behavioral testing groups (cohorts) ensuring only one male pup per gestational and postnatal litter assigned for any one endpoint. [Cohort 1: running wheel (RW; PND24), elevated plus maze (EPM; PND30), passive avoidance (PA; PND55), hot plate; Cohort 2: EPM (PND29); Ymaze (PND38); Cohort 3: motor activity (MA; PND40), light/ dark place preference (L/D; PND43), Morris water maze (MWM; PND60); Cohort 4: pre-pulse startle inhibition (PPI; PND61-63), adult EPM (PND70)]. Excess male pups were identified as unassigned. Female pups were not used. Age of eye-opening for both eyes was similar across groups. Male pups weaned on PND21 were group-housed 2-3 per cage depending on the final terminal age on study to adhere to housing guidelines. When examined as adults, (> PND90), rats in the $20 \mathrm{ppm} \mathrm{F}^{-}$dose group showed evidence of mild fluorosis (Supplementary Fig. S1) similar to that reported by Catani et al. (2010) after 78 days of 25 ppm F$^{-}$exposure.

\section{Behavioral Testing}

Handling of rats for behavioral testing followed NTP guidelines for neurobehavioral testing (NTP 2015). All testing was conducted between 10:00-15:00 h. Assignment of rats to testing apparatus and time of testing was counterbalanced. Body weights were similar across groups prior to the start of testing for PA, PPI, or MWM (Supplementary Table S1). Accurate camera tracking by Ethovision XT 11.5 (Noldus, Wageningen, the Netherlands) was confirmed for each rat and incorrect points were edited and corrected per Noldus manual.

Running Wheel Activity PND24 rats were transferred to testing room and allowed to acclimate under identical housing conditions for $24 \mathrm{~h}$. Individual rats were transferred to a filter-top cage $(396 \times 215 \times 172 \mathrm{~mm})$ with a stainless steel RW (Mini-Mitter®; Respironics Co., Bend, OR) that limited light levels to 91 and $8 \mathrm{~lm}$ for light/dark periods, respectively. Computer-assisted recording of wheel revolutions in 15-min epochs (Vital View Data Acquisition, Respironics Co.) were collected over dark (18:00-6:00 EST) and light (6:00-18:00 EST) phases. Original food and water exposure was maintained. A linear mixed-effects repeated measures ANOVA (RM ANOVA) was used to analyze total daily RW rotations for the dark and light phases.
Elevated Plus Maze To assess exploratory activity and anxietyrelated performance (Walf and Frye 2007), naïve rats (PND30), rats with prior RW experience (PND31), and a separate group of naïve adult rats (PND72) were assessed in the EPM (a dark plexiglass apparatus: central area $(10 \times 10 \mathrm{~cm})$, two opposing open arms $(50 \times 10 \mathrm{~cm})$, two opposing enclosed arms $(50 \times 10 \times 40 \mathrm{~cm}))$ elevated $50 \mathrm{~cm}$ above a dark floor. Each rat was placed in the central area facing an open arm and allowed $7 \mathrm{~min}$ to freely explore. Based on previous reports of a diminished EPM "cautious response" in fluoride exposed rats (Bartos et al. 2015), an additional testing paradigm was used to examine PND30 rats of G2 and G4. The paradigm was modified to include a linear-shadow cast over the maze as representative of a predator. Behavior was videocaptured (Ethovision XT 11.5 Applications Manual) and the number of entries, percent time spent, and total distance traveled in arms were recorded. Wilcoxon Rank Sum tests were used to analyze number of entries and duration. Student's $t$ tests were used to analyze distance traveled.

Locomotor Activity On PND40, exploratory motor activity was measured in an open field chamber $(42 \times 42 \mathrm{~cm}$; Columbus Instruments, Columbus, $\mathrm{OH})$ outfitted with photocell detectors $(0.32 \mathrm{~cm}$ diameter) spaced $5 \mathrm{~cm}$ from floor and $1.27 \mathrm{~cm}$ linearly apart around the chamber. Ambulatory activity was recorded in 5-min epochs over a 45-min test session. Total ambulatory activity, time spent in the margin (one-photocell width from the wall), and activity within the center area $(20 \times 20 \mathrm{~cm})$ were recorded. Student's $t$ tests were used to analyze total ambulatory activity, total ambulatory time, total distance traveled, and ambulatory activity acclimation. Wilcoxon Rank Sum tests were used to analyze activity total margin time, margin distance, and center distance traveled. RM ANOVA was used to analyze ambulatory activity in 5min epochs.

Light/Dark Place Preference To examine exploratory activity and preference for the dark chamber, a PND43 rat was placed in the lighted side of a 2 -sided plexiglass chamber $(68 \times 21 \times$ $34 \mathrm{~cm}$; with a clear and a dark chamber, $34 \times 21 \times 34 \mathrm{~cm}$ ). For $5 \mathrm{~min}$, entries into and total time spend in lighted side were video-captured (Ethovision XT) and analyzed by Wilcoxon Rank Sum tests.

Passive Avoidance The ability of a rat to learn to withhold a normally preferred response was assessed using a Gemini Avoidance System (San Diego Instruments, San Diego, CA). On PND55, a rat was placed into the start chamber modified by a white covering on back and side walls with the gate closed. After $120 \mathrm{~s}$, the house light and cue light were turned on and the gate raised. Upon crossing to the dark side, the gate closed and a 3-s 0.5-mA floor-grid shock was delivered. The rat was removed after $10 \mathrm{~s}$. This sequence was repeated every 
$24 \mathrm{~h}$. Response latency was recorded with a maximum of $300 \mathrm{~s}$. RM ANOVA was used to analyze latency over sessions, excluding day 1 . The relative change from the first trial to the last trial was analyzed by Kruskal-Wallis rank sum test and Wilcoxon rank sum test. The percent reaching maximum was analyzed by Fisher's exact test.

Hot-Plate Latency Forty-eight hours after cessation of PA, pain threshold was determined as the latency to respond (jump or link of hindpaw; 2-min cutoff) to being placed on a $55^{\circ} \mathrm{C}$ hot-plate platform (IITC Life Science, Woodland Hills, CA). Latency was analyzed by Student's $t$ test.

Startle Response and Pre-Pulse Startle Inhibition PND 61-62 rats were assessed for auditory startle response, habituation, and PPI as a measure of sensorimotor gating using a computer-assisted SR-LAB startle apparatus (San Diego Instruments). Background noise level was set at $65 \mathrm{~dB}$. Following a 5-min habituation period, the session began with a $120-\mathrm{dB}$ trial, followed by $5120 \mathrm{~dB}$ trials; 2 blocks of 31 trials [2 no-stimulus trials, 6 acoustic startle stimuli (40-msec null period followed by $40-\mathrm{msec} 120 \mathrm{~dB}$ pulse) trials alone, 18 prepulse stimulus trials $(40-\mathrm{msec}$ null period followed by 20 msec pre-pulse of $68,71,77$, and $80 \mathrm{~dB}$ followed by a 100 msec null period and a $40-\mathrm{msec} 120-\mathrm{dB}$ pulse; for an entire recording period of $200 \mathrm{msec}$ ) presented in a random order, followed by $120-\mathrm{dB}$ trials. Trials were presented at $15 \mathrm{~s}$ variable inter-trial intervals (ITI; 5-25 s). Habituation was calculated as difference between first and the last block of 120-dB trials. Pre-pulse startle inhibition was calculated as a percentage of the median $120 \mathrm{~dB}$ startle response. Wilcoxon Rank Sum tests were used to analyze the first $120 \mathrm{~dB}$ (Vmax) responses and startle habituation. RM ANOVA was used to analyze 120-dB startle responses (Vmax). Pre-pulse startle inhibition was analyzed by two-way ANOVA with dose and pre-pulse type as factors. Negative PPI values were set to 0 .

Morris Water Maze PND60 rats were transferred to the testing room $24 \mathrm{~h}$ prior to testing and maintained under normal homecage conditions. A circular plastic tank $(183 \times 62 \mathrm{~cm})$ filled with opaque water to $52 \mathrm{~cm}(10 \mathrm{~cm}$ distance from the water surface to the lip of tank) was allowed to equilibrate to room temperature $\left(25^{\circ} \mathrm{C}\right)$. Water was changed every 2 days. For cued learning, days 1 and 2, white curtains surrounded the tank (NTP 2015) and a clear visible plexiglass platform (10cm diameter; Stoelting; Wood Dale, IL) was placed within one quadrant of the pool, $36 \mathrm{~cm}$ from the tank wall and raised $1.5 \mathrm{~cm}$ above the water and identified with a flag. The rat was placed into the pool in the quadrant opposite the platform, facing the wall of the tank and allowed $90 \mathrm{~s}$ to find the platform. The rat remained on the platform for $20 \mathrm{~s}$ before removal. Three trials, $10 \mathrm{~min}$ ITI, were run daily for 2 days. The platform location changed daily. For spatial learning, four geometrical figures $(1 \times 1 \mathrm{~m})$ were placed on curtain walls at tank rim level as cues. The platform was submerged $(1.5 \mathrm{~cm})$ in a quadrant different from cued learning. Rats were placed in the tank within a pre-assigned quadrant and allowed $90 \mathrm{~s}$ to find platform. Three daily trials, alternating start location, were administered (10-min ITI). Rats were trained seven consecutive days, reaching the criteria of $>85 \%$ of control animals showing a $>50 \%$ decrease from original latency. A probe test was conducted $24 \mathrm{~h}$ following the final training trial to examine reference memory. The platform was removed and rats placed within quadrant opposite to goal quadrant (GQ) for $90 \mathrm{~s}$. Reversal learning was initiated $48 \mathrm{~h}$ later. With the platform in a new quadrant, hidden platform training was conducted (three trials/day; 4 days). A probe test was conducted $24 \mathrm{~h}$ later. Video-captured images were analyzed using Ethovision XT. Acquisition was measured by latency to reach the platform zone (PZ; expanded to $15 \mathrm{~cm}$ (Blokland et al. 2004; Vorhees and Williams 2006). In the probe tests, latency to the first entry into GQ or PZ was recorded. The number of visits to the PZ, number of visits to each quadrant, and total time in each quadrant were recorded for each 30-s epoch. Wilcoxon Rank Sum tests were used to analyze latency on the first trial of cued learning. For each day, mean daily latencies were calculated and analyzed within each test phase of the MWM by RM ANOVAs employing a mixed model with autoregressive (1) (AR(1)) covariance due to the correlation between days. Comparisons across dose groups for any 1 day were analyzed by ANOVA. In the hidden platform sessions, the percentage of improvement in learning was calculated as the change in latency from first to last day and analyzed by Wilcoxon rank sum test. In the probe tests, latency to the first entry into GQ or PZ was analyzed by Kruskal-Wallis test and Wilcoxon rank sum test. Number of entries and duration spent in each quadrant were analyzed by a RM-ANOVA with epoch and quadrant as factors.

Y-Maze With shipment 4, the Y-maze task was included as an additional assessment of spatial learning using a continuous spontaneous alternation paradigm (Lalonde 2002). PND38 rats from $\mathrm{G} 2$ and $\mathrm{G} 4$ were placed in the center intersection of a black, plexiglass Y-maze with 3 equal arms $(56 \times 10$ $\mathrm{x} 25 \mathrm{~cm})$ and allowed to explore for $7 \mathrm{~min}$. Video-captured images were analyzed for arm entries using Ethovision XT. Sequential reentries into an arm were excluded and percent alternation was calculated as the number of triads containing entries into all three arms/maximum possible alternations. Wilcoxon Rank Sum tests were used to analyze the number of entries and \% alternation.

\section{Tissue Collection and Fluoride Analysis}

Following completion of MWM testing, samples were collected from rats randomly selected from shipments 3 and 4 . Blood 
was collected via a cardiac puncture from rats deeply anesthetized under $\mathrm{CO}_{2}$ and plasma separated by centrifugation in EDTA-free, heparin coated plasma tubes (\# 367874, Becton Dickinson, Franklin Lakes, NJ). The brain and femur were excised, immediately frozen on dry ice, and stored at $-80^{\circ} \mathrm{C}$. Cleaned femur samples $(5-8 \mathrm{mg})$ were ashed $\left(8 \mathrm{~h} ; 590{ }^{\circ} \mathrm{C}\right)$, pulverized, and weighed. Brain samples were homogenized in 3-ml di- $\mathrm{H}_{2} \mathrm{O}$. For PND25 assessment, the brain and femur samples were obtained from randomly selected unassigned male rats. Duplicate samples were analyzed using a modification of the hexamethyldisiloxane microdiffusion method of Taves and Neuman (1964) and detected with a fluoride ion-specific electrode and a pH/ISE meter. Urine was collected in metabolism cages (Techniplast) from individual rats $(n=10)$ in $\mathrm{G} 2$ and G4 between 9:00-13:00 $\mathrm{h}$ and frozen. No water was provided over this interval. Urine samples $<200 \mu \mathrm{l}$ were excluded. A $100-\mu l$ aliquot of urine was analyzed for creatinine using a kinetic modification of the Jaffe procedure (Moore and Sharer 2017). The rate of change at 520/800 nm was determined using the Olympus AU400e clinical analyzer (Beckman-Coulter Irving, TX).

\section{Tissue Collection, Staining, and Histological Analysis}

The kidney, liver, and reproductive system organs were collected following $\mathrm{CO}_{2}$ euthanasia at the termination of behavioral testing from randomly selected adult rats (> PND80) in cohorts 3 and 4 of shipment $3(n=8-13)$. The liver and kidney were immersion fixed in $10 \%$ neutral buffered formalin. Testes and epididymis were immersion fixed $24 \mathrm{~h}$ in Davidson's. Samples were trimmed, ethanol dehydrated, embedded in paraffin, and $5 \mu \mathrm{m}$ sections cut and stained with Hematoxylin and eosin (H\&E). Randomly selected rats from G2 and G4 ( $n=6$; cohort 4) were deeply anesthetized with Fatal-Plus (Vortech Pharmaceuticals, Ltd., Dearborn, MI), whole body perfused with saline followed by $4 \%$ paraformaldehyde/phosphate buffered saline, and post-fix overnight at $4{ }^{\circ} \mathrm{C}$. Brains were excised, transected in the mid-sagittal plane, and processed for paraffin embedding. H\&E stained sections from each hemisphere $(8 \mu \mathrm{m})$ were selected to represent a consistent plane of cut containing the hippocampus (lateral 1.35-1.95 $\mathrm{mm}$ ) and immunostained for astrocytes and microglia. Endogenous peroxidase activity was quenched with $3 \% \mathrm{H}_{2} \mathrm{O}_{2}$ followed by heat-induced epitope retrieval $(0.01 \mathrm{M}$ citrate buffer $\mathrm{pH}$ 6.0; Biocare Medical, Concord, CA). Non-specific binding was blocked with avidin/biotin (Vector Labs, Burlingame, CA) and 10\% normal goat serum (Jackson Immunoresearch, West Grove, PA). Sections were incubated with rabbit anti-cow glial fibrillary acidic protein (Dako GFAP; 1:7000; RT; 30 min; Agilent Technologies, Carpinteria, CA) then incubated with biotinylated goat anti-rabbit IgG (1:500; Vector-Labs) and detected with Vectastain Elite ABC R.T.U. (Vector Labs); 3,3- diaminobenzidine (DAB, Agilent Technologies). Microglia were identified with a rabbit polyclonal antibody to ionized calcium-binding adaptor molecule 1 (Iba-1, 1:600, $1 \mathrm{~h}, 24^{\circ} \mathrm{C}$; Wako Chemicals, Richmond, VA) following microwave antigen retrieval. Defined regions of interest (ROI) of the suprapyramidal blade of the dentate gryus and the CA1 pyramidal layer were evaluated. Brain sections were scanned under $\times 20$ magnification (Aperio ScanScope T2 scanner, Aperio Technologies, Inc., Vista, CA) and viewed using Aperio ImageScope v.6.25.0.1117. Stained slides were assigned random numbers and blinded for evaluation.

\section{Thyroid Hormone Analysis}

From cohort 1 in shipment 3, six rats (PND56) per group were randomly selected and blood collected via cardiac puncture under $\mathrm{CO}_{2}$ anesthesia. Serum triiodothyronine (T3) and thyroxine (T4) analyses were performed using $\mathrm{I}^{125}$ radioimmunoassays (MP biomedicals LLC; Costa Mesa CA) following manufacturer's instructions. A $100-\mu$ l aliquot of serum was incubated with $1 \mathrm{ml}$ of $\mathrm{T} 3 \operatorname{tracer}\left(37^{\circ} \mathrm{C}\right.$; $\left.60 \mathrm{~min}\right)$ and radioactivity determined (APEX gamma counter; ICN Microbiomedic Systems, Huntsville, AL). For T4 determination, samples and standards $(2-20 \mathrm{ng} / \mathrm{dl})$ were incubated with $\mathrm{T} 4$ tracer (RT; $60 \mathrm{~min}$ ) and processed as described for T3. The percent trace level was calculated and $\mathrm{ng} / \mathrm{dl}$ determined from standard curve as adjusted for non-specific binding. Serum samples were assayed for thyroid stimulating hormone (TSH) (Rat Pituitary Magnetic Bead Panel Kit (Cat. no. RPTMAG-86K); EMD Millipore Corporation, Billerica, MA) according to manufacturer's protocol. Briefly, 25- $\mu$ l aliquot (diluted 1:3) was incubated in $200 \mu \mathrm{l}$ of assay buffer with TSH magnetic beads $(25 \mu \mathrm{l})$ overnight at $4{ }^{\circ} \mathrm{C}$. Samples were washed, incubated with $50-\mu l$ detection antibody (RT, $30 \mathrm{~min}$ ) followed by $50 \mu 1$ of streptavidin-phycoerythrin (RT; $30 \mathrm{~min}$ ), washed, $100 \mu \mathrm{l}$ of Sheath Fluid added ( $5 \mathrm{~min}, \mathrm{RT}$ ) then a specific spectral address detected by phycoerythrin immediately analyzed (Luminex xPONENT; Luminex Corp., Austin, TX) using a fluorescent bead-based multiplexing system (LiquiChip-200; QIAGEN, Valencia, CA).

\section{Statistical Analysis}

While fluorine is considered an essential element in human diet, how this applies to rodents is not known; however, lowering $\mathrm{F}^{-}$levels in the specialized low- $\mathrm{F}^{-}$chow to approximately 3 ppm had no impact on gestational outcome, eye-opening, and body weight. This allowed us to make comparisons across the drinking water dose groups maintained on the vehicle low$\mathrm{F}^{-}$chow. The experimental design for statistical analysis adhered to the following. Differences between G1 (control chow) and $\mathrm{G} 2$ (low- $\mathrm{F}^{-}$chow) rats receiving $\mathrm{RO}-\mathrm{H}_{2} \mathrm{O}$ for behavioral endpoints were assessed to confirm that the lower 
level of fluoride in the diet did not alter the normal expected pattern of behavior. Differences between G2 and G3 (10 ppm F $\left.\mathrm{F}^{-}\right)$or $\mathrm{G} 4\left(20 \mathrm{ppm} \mathrm{F}^{-}\right)$were tested to evaluate effects of fluoride in the drinking water on rats maintained on the low- $\mathrm{F}^{-}$chow. Data were tested for homogeneity of variance using Levene's tests and for nonnormality using Shapiro-Wilk tests. Statistical significance was set at two-tailed $p<0.05$. Group sizes were statistically determined as sufficient for detecting significant differences from controls at $p<0.05$. In the absence of a significant interaction between shipment and exposure, shipment was not included as a factor in the final analysis. Analyses of $\mathrm{F}^{-}$levels and levels of T3, T4, and TSH were conducted with Wilcoxon rank sum tests (G1 vs. G2) and Kruskal Wallis tests (G2, 3, and 4). Post-hoc comparisons were conducted with Dunn's multiple comparisons tests. Specific analyses conducted for behavioral tests are reported in relevant methods sections. Statistical analyses were performed using GraphPad Prism 7 (GraphPad Software, Inc., La Jolla, CA); SAS 9.37 (SAS Institute, Cary, NC), and R (R Core Team 2016).

\section{Results}

\section{Behavioral Assessments}

RW Activity All rats displayed a normal diurnal cycle with increased activity during the dark phase (dark areas) compared to light phase (Fig. 1a, b). A linear mixed-effects RMANOVA for daily dark or light phase rotations over 2 days showed similar activity across groups G1 and G2, and G3 (10 ppm $\mathrm{F}^{-}$; Fig. 1a). From shipment 4, G2 and G4 rats were evaluated on the RW for an extended 5-day period with no significant differences observed across groups (Fig. 1b).

Locomotor Activity All rats showed a decrease in ambulatory activity over time indicative of acclimation to the novel environment (Fig. 2a, d). There was no evidence of an alteration in the normal exploratory activity in a novel environment and no statistically significant differences observed across groups in center arena activity (Fig. 2b, e) or time spent in margin (Fig. 2c, f).

Elevated Plus Maze The elevated plus maze utilizes the natural conflict of a rodent under bright illumination conditions to avoid an open area for fear of danger versus exploration of a novel environment. Young behaviorally naïve rats showed no differences between groups for the number of entries into the open arm and the percentage of the total session spent in the open arms (Table 1). Prior experience to behavioral assessment on the RW did not alter EPM performance and no differences were observed between groups (Table 1). In adult rats, an overall increase in exploratory activity was observed with higher number of entries and percent time spent in the open arms than that seen in young rats. No differences were observed across groups (Table 1). With the modification of the EPM paradigm to include a "predatory threat," rats showed decreased time spent in the open arms. No differences were observed between groups. For approximately $90 \%$ of the session, rats remained within the enclosed arms, entering into the open arms less than two times. No evidence of freezing behavior was detected.

Light/Dark Place Preference Examination of exploratory activity, reinforcement value of a dark chamber, and "anxiety" by light/dark place preference showed no differences between groups. The number of entries into the lighted side of the chamber (Fig. 3a) and the percent time spent within this chamber (Fig. 3b) showed no differences across groups in exploratory activity into the lighted side or preference for the dark chamber.

Hot Plate Latency No differences in response latency to a $55{ }^{\circ} \mathrm{C}$ hot plate were observed between control groups and

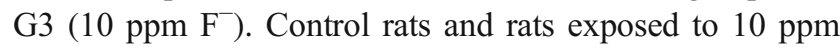
showed no difference in latency. In rats exposed to $20 \mathrm{ppm}$ $\mathrm{F}^{-}$(G4), significantly shorter response latencies were observed $(p<0.002$; Fig. $3 c)$ indicative of hyperanalgesia.

Passive Avoidance In all rats, latency to cross to the dark side was significantly increased $(p<0.01)$ over test sessions (Fig. $3 d$ ). No significant differences were observed across groups with a mean increase of between 190 and $230 \mathrm{~s}$ and a similar proportion of rats reached the maximum $300 \mathrm{~s}$ cutoff.

Startle Reactivity and PPI Rats were assessed for auditory reflex response and sensory/motor gating. The first response to the novel auditory stimuli was not significantly different across groups. Habituation of the reflex response occurred over repeated trials, as evidenced by a progressive decrease in $120 \mathrm{~dB} V \max$, was similar for all groups (Fig. 3e). No differences were observed for Vmax recorded during no-stimulus trials. PPI was demonstrated for all rats and increased with increasing pre-pulse intensity levels $(p<0.0001$; Fig. 3f). No group differences were observed for PPI at each pre-pulse intensity.

Y-Maze To expand the evaluation of rats exposed to the higher dose level of $20 \mathrm{ppm} \mathrm{F}^{-}$, Y-maze performance was included to examine the willingness of rats to explore a new environment and the memory of the previously entered arm (Fig. 3g). No significant differences were observed across groups in the number of arm entries suggesting an equivalent level of exploratory activity. No significant differences were observed in across groups in 

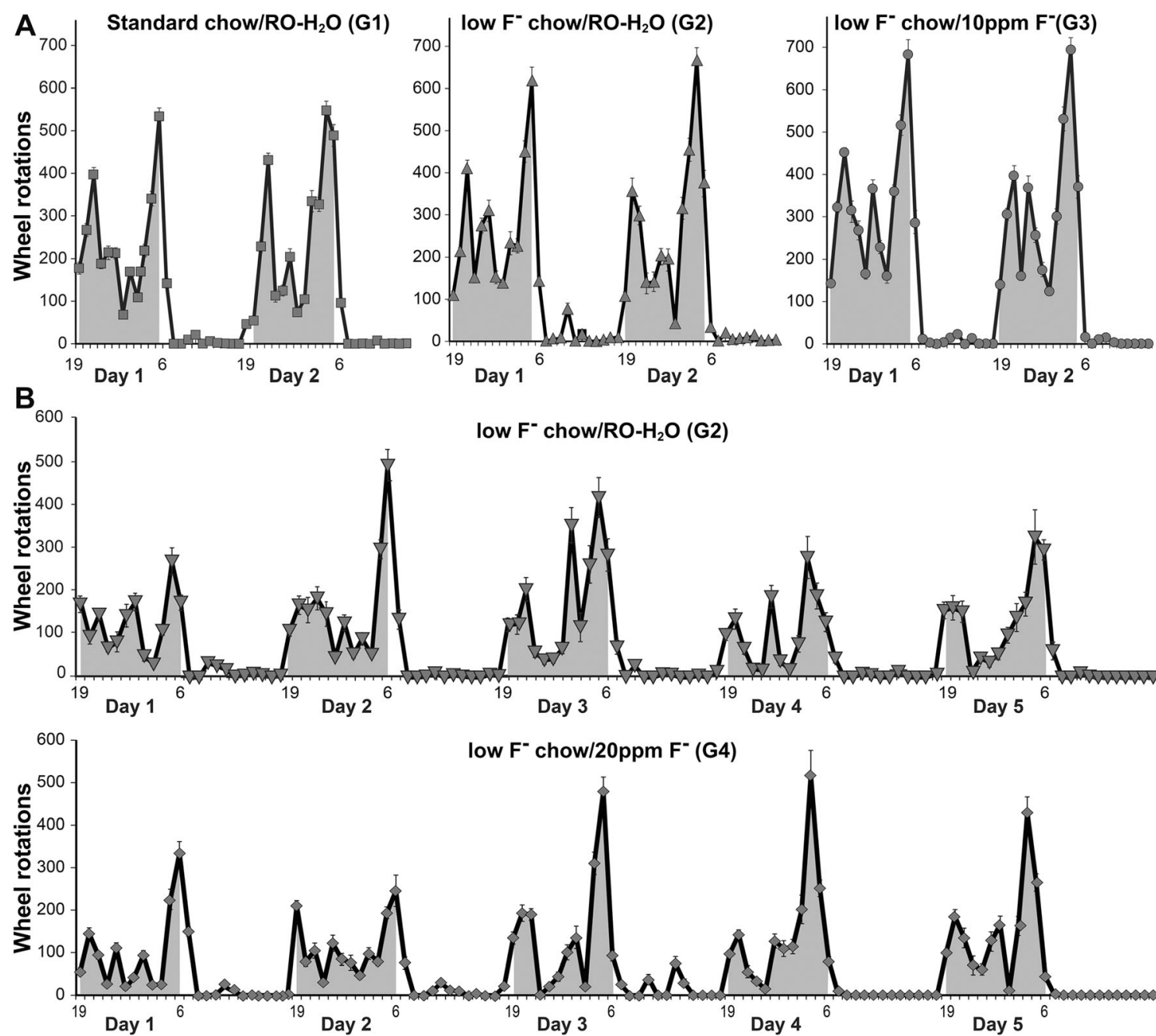

low $\mathrm{F}^{-}$chow/20ppm F- (G4)

low $\mathrm{F}^{-}$chow/RO- $\mathrm{H}_{2} \mathrm{O}(\mathrm{G} 2)$
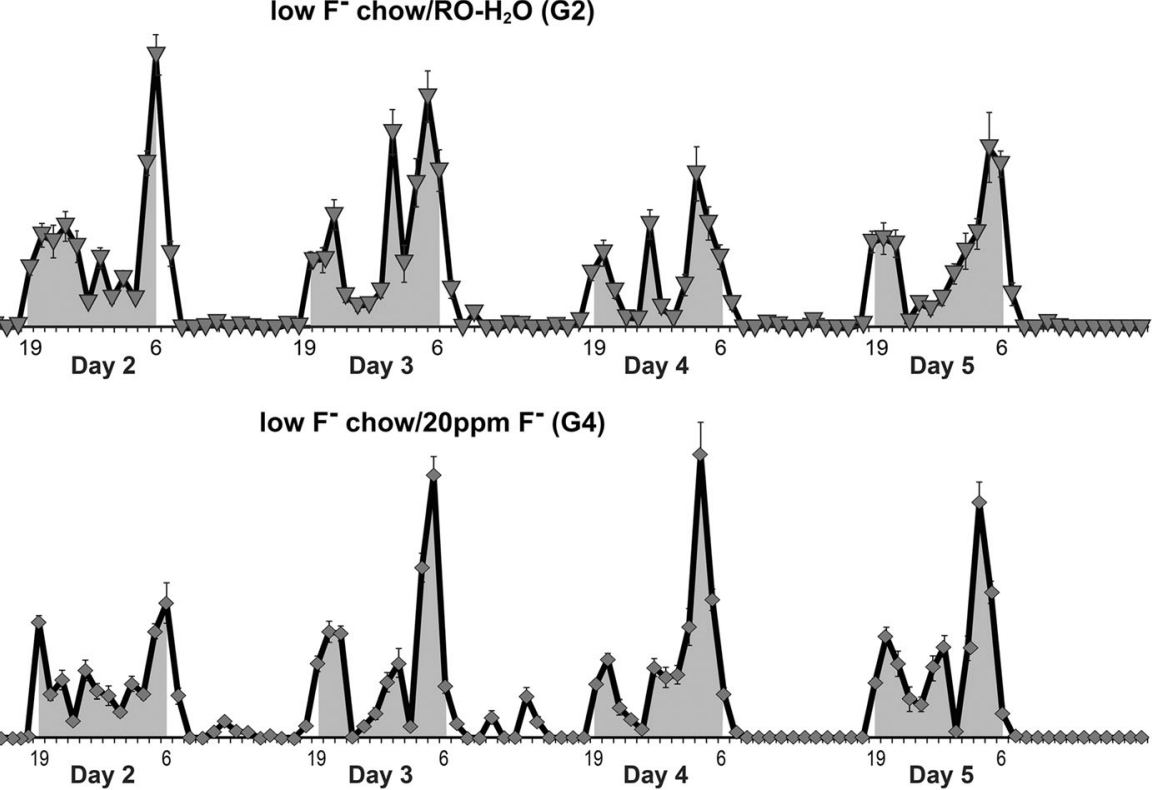

Fig. 1 Running Wheel activity in postnatal day (PND) 25 Long-Evans hooded male rats. (a) Mean hourly wheel rotations during light and dark phases over 2 days. G1: standard chow $/ \mathrm{RO}^{-} \mathrm{H}_{2} \mathrm{O}(n=15)$; $\mathrm{G} 2$ : low- $\mathrm{F}^{-}$ chow $/ \mathrm{RO}-\mathrm{H}_{2} \mathrm{O}(n=15)$; and $\mathrm{G} 3$ : low- $\mathrm{F}^{-}$chow $/ 10$ ppm $\mathrm{F}^{-}$drinking water $(n=16)$. Drinking water exposure began on gestational day 6. (b) Mean hourly wheel rotations over 5 days (mean $\pm \mathrm{SEM})$ for $\mathrm{G} 2(n=10)$ and $\mathrm{G} 4$ : low- $\mathrm{F}^{-}$chow $/ 20$ ppm $\mathrm{F}^{-}$drinking water $(n=10)$. Shaded areas represent dark phase of elevated activity memory of the previously entered arm and the preference for examining an alternate arm (percent alternation).

MWM In the first trial of cued learning and the first trial of hidden platform acquisition, the latency for reaching the visible platform was similar across groups (Fig. 4a). Latency decreased on day 2 with no significant differences seen across groups. In hidden platform spatial training, latency on the first day was not significantly different across groups (Fig. 4a) demonstrating similar initial performance. Learning was demonstrated by progressively shorter latencies over sessions (i.e., acquisition) in all groups (Fig. 4a). Overall, G4 rats exposed to $20 \mathrm{ppm} \mathrm{F}^{-}$ showed significantly shorter latencies to find the hidden platform $\left(\mathrm{F}_{(1,30)}=10.43 ; p<0.005\right)$, statistically significant on days 2 and 3 , as compared to controls $(p<0.05$; Fig. 4a). "Blinded" video tracking verification identified three $\mathrm{G} 2$ rats that floated upon entry into the pool. When excluded from the analysis, G2 continued to show significantly longer latencies than G4 across the session $\left(\mathrm{F}_{(1,27)}=8.77 ; p<0.05\right)$. No significant difference in path length was observed between groups (Supplementary Fig. S2a) suggesting that the difference in latency was not related to a difference in path selection to the platform. Memory was assessed in the probe test as latency to reach the previous platform location (platform zone, PZ) and preference for the goal quadrant (GQ). No significant differences were observed across G1, G2, and G3 (10 ppm $\mathrm{F}^{-}$) in latencies to reach the GQ or PZ (Fig. 4b). Similar to hidden platform training, rats exposed to $20 \mathrm{ppm} \mathrm{F}^{-}$ (G4) showed shorter latencies to reach the GQ $(p<0.05)$ or PZ ( $p<0.01$; Fig. 4b). "Floating" was observed in the same three rats identified in the hidden platform training. If these were excluded from analysis, significant 

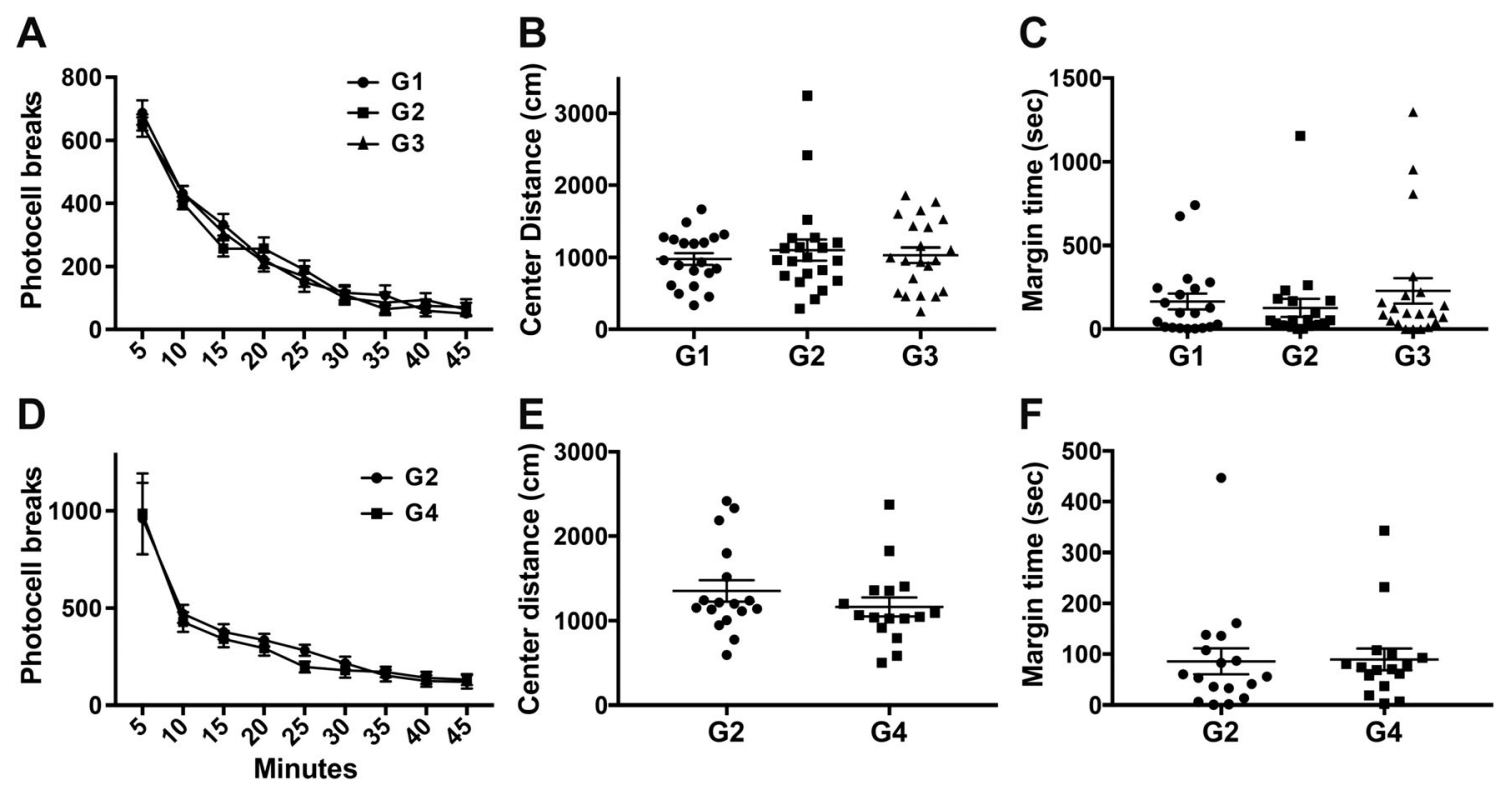

Fig. 2 Open-Field activity in postnatal day (PND) 40 Long-Evans hooded male rats. (a) Ambulatory activity in open field in 5-min epochs (data represents mean $\pm \mathrm{SEM})$. (b) Total distance $(\mathrm{cm})$ traveled in the center of the arena and (c) total time spent in the margin of the arena over 45-min session (data represents mean \pm SEM and individual animal response). G1: standard chow/ $\mathrm{RO}-\mathrm{H}_{2} \mathrm{O}(n=20)$; $\mathrm{G} 2$ : low- $\mathrm{F}^{-}$ chow $/ \mathrm{RO}-\mathrm{H}_{2} \mathrm{O}(n=21)$; $\mathrm{G} 3$ : low- $\mathrm{F}^{-}$chow $/ 10$ ppm $\mathrm{F}^{-}$drinking water $(n=21)$. (d) Ambulatory activity, (e) distance traveled in center, and (f) margin time for $\mathrm{G} 2(n=17)$ and $\mathrm{G} 4$ : low- $\mathrm{F}^{-}$chow/20 ppm $\mathrm{F}^{-}$drinking water $(n=16)$. Drinking water exposure began on gestational day 6 differences in latency were no longer evident for the GQ. Preference for the GQ was evaluated for the entire 90-s session and 30-s epochs. A clear preference for the GQ was observed with number of visits (Fig. 4c). A preference for GQ was not observed with time spent (Fig. 4d) with similar values seen for the GQ and start quadrant (SQ). To further examine learning capability and flexibility to shift and learn a new escape location, reversal learning trials were conducted. All rats displayed shorter latencies on the first day of reversal learning as compared to the first day of hidden platform training. All groups showed a significant decrease in latency over reversal learning sessions $(p<0.001$; Fig. 5a). Rats exposed to $20 \mathrm{ppm} \mathrm{F}^{-}$showed overall shorter latencies across the

Table 1 Elevated plus maze performance of Long-Evans hooded rats following drinking water exposure to fluoride

\begin{tabular}{|c|c|c|c|c|c|c|c|c|c|}
\hline & \multicolumn{3}{|c|}{ PND 30 naive } & \multicolumn{3}{|c|}{ PND 30 RW } & \multicolumn{3}{|l|}{ Adult } \\
\hline & G1 & G2 & G3 & G1 & G2 & G3 & G1 & G2 & G3 \\
\hline & $(n=18)$ & $(n=20)$ & $(10 \mathrm{ppm})(n=23)$ & $(n=19)$ & $(n=21)$ & $(10 \mathrm{ppm})(n=22)$ & $(n=19)$ & $(n=19)$ & $(10 \mathrm{ppm})(n=22)$ \\
\hline Open arm entries & $3.6 \pm 0.6$ & $3.0 \pm 0.7$ & $3.5 \pm 0.6$ & $4.4 \pm 0.9$ & $4.7 \pm 0.6$ & $3.5 \pm 0.5$ & $8.2 \pm 1.1$ & $8.6 \pm 1.5$ & $8.7 \pm 1.5$ \\
\hline Open arm duration $\%$ & $8.2 \pm 1.9$ & $9.1 \pm 2.5$ & $12.3 \pm 2.6$ & $8.2 \pm 1.6$ & $11.1 \pm 2.2$ & $9.8 \pm 1.6$ & $16.9 \pm 2.2$ & $14.9 \pm 1.8$ & $16.6 \pm 1.8$ \\
\hline \multirow[t]{4}{*}{ Closed arm entries } & $7.0 \pm 0.8$ & $7.4 \pm 0.7$ & $7.2 \pm 1.0$ & $10.1 \pm 1.2$ & $7.8 \pm 0.8$ & $8.9 \pm 1.1$ & $17.7 \pm 1.4$ & $15.4 \pm 1.7$ & $16.1 \pm 2.2$ \\
\hline & \multicolumn{3}{|c|}{ PND 30 predator } & \multicolumn{3}{|c|}{ PND 30 RW } & \multicolumn{3}{|l|}{ Adult } \\
\hline & $\mathrm{G} 2$ & \multicolumn{2}{|l|}{ G4 } & G2 & \multicolumn{2}{|l|}{ G4 } & $\mathrm{G} 2$ & \multicolumn{2}{|l|}{ G4 } \\
\hline & $(n=11)$ & \multicolumn{2}{|c|}{$(20 \mathrm{ppm})(n=10)$} & $(n=17)$ & \multicolumn{2}{|c|}{$(20 \mathrm{ppm})(n=19)$} & $(n=16)$ & \multicolumn{2}{|c|}{$(20 \mathrm{ppm})(n=16)$} \\
\hline Open arm entries & $0.6 \pm 0.3$ & \multicolumn{2}{|l|}{$0.7 \pm 0.3$} & $3.4 \pm 0.6$ & \multicolumn{2}{|l|}{$2.5 \pm 0.5$} & $8.4 \pm 1.8$ & \multicolumn{2}{|l|}{$9.9 \pm 1.5$} \\
\hline Open arm duration $\%$ & $0.5 \pm 0.4$ & \multicolumn{2}{|l|}{$1.1 \pm 0.6$} & $8.3 \pm 1.9$ & \multicolumn{2}{|l|}{$6.3 \pm 1.8$} & $9.7 \pm 1.7$ & \multicolumn{2}{|l|}{10.6} \\
\hline Closed arm entries & $6.6 \pm 0.9$ & \multicolumn{2}{|l|}{$6.1 \pm 0.7$} & $9.1 \pm 0.9$ & \multicolumn{2}{|l|}{$7.4 \pm 0.9$} & $18.1 \pm 2.3$ & \multicolumn{2}{|l|}{$19.4 \pm 2.0$} \\
\hline
\end{tabular}

Data represents mean $\pm \mathrm{SEM}$

Rats were exposed from gestational day 6

G1: standard chow (Teklad 2918)/RO- $\mathrm{H}_{2} \mathrm{O}$

G2: low-F ${ }^{-}$chow (Teklad TD.160173)/RO- $\mathrm{H}_{2} \mathrm{O}$

G3: low- $\mathrm{F}^{-}$chow (Teklad TD.160173)/10 ppm $\mathrm{F}^{-}$drinking water

G4: low- $\mathrm{F}^{-}$chow (Teklad TD.160173)/20 ppm F$^{-}$drinking water 
A

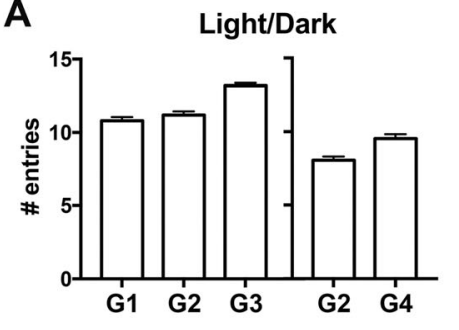

D Passive Avoidance

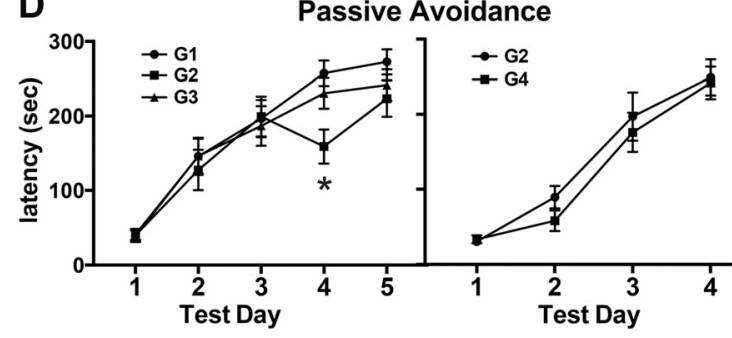

F

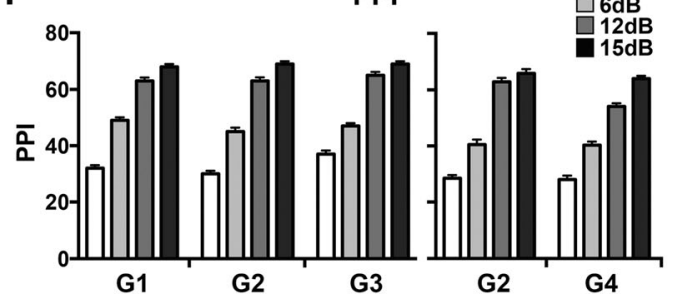

Fig. 3 Light/dark place preference, hot-plate latency, passive avoidance, startle response, pre-pulse startle inhibition, Y-maze in Long-Evans hooded male rats. (a-b) Light/dark place preference at postnatal day (PND) 42. (a) Number of entries and (b) percent total time spend in lighted side. $\mathrm{G} 1$ : standard chow $/ \mathrm{RO}-\mathrm{H}_{2} \mathrm{O}(n=20)$; $\mathrm{G} 2$ : low- $\mathrm{F}^{-}$ chow $/ \mathrm{RO}-\mathrm{H}_{2} \mathrm{O}(n=21)$; $\mathrm{G} 3$ : low- $\mathrm{F}^{-}$chow/10 ppm $\mathrm{F}^{-}$drinking water $(n=21)$ and $\mathrm{G} 2(n=16)$ and $\mathrm{G} 4$ : low- $\mathrm{F}^{-}$chow/20 ppm F $\mathrm{F}^{-}$drinking water $(n=17)$. (c) Hot-plate latency at PND60 (G1: $n=13$; G2: $n=13$; G3: $n=14$; and G2: $n=16$, G4: $n=14$ ). (d) Passive avoidance latency

session $\left(\mathrm{F}_{(1,30)}=5.56 ; p<0.05\right)$ with post hoc analysis showing significantly shorter latencies on day 2 as compared to G2 ( $p<0.05$; Fig. 4a). Due to the shorter latencies observed, distance traveled was examined in G2 and G4. No differences were observed between groups (Supplementary Fig. S2b). On the probe trial, no significant differences were observed in the initial latency to reach the GQ or PZ (Fig. 5b), number of visits or time spent in GQ (Fig. 5c, d).

\section{Fluoride Levels}

In 25-day-old rats (Table 2), differences were observed for $\mathrm{F}^{-}$ levels in the brain as a function of chow with significantly lower levels observed in the low- $\mathrm{F}^{-}$chow control rats $(\mathrm{G} 2)$ as compared to normal chow $\mathrm{G} 1(p<0.001)$. The addition of fluoride to the drinking water significantly elevated $\mathrm{F}^{-}$levels in the brain over those seen in G2 $(p<0.01)$. The approximately $2 \times$ increase in brain levels in G4 with exposure to 20 ppm $\mathrm{F}^{-}$over levels in $\mathrm{G} 310 \mathrm{ppm} \mathrm{F}^{-}$failed to reach

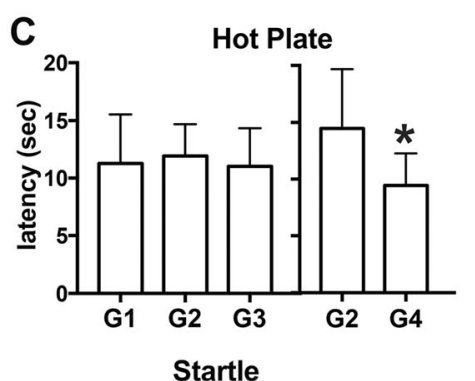

E
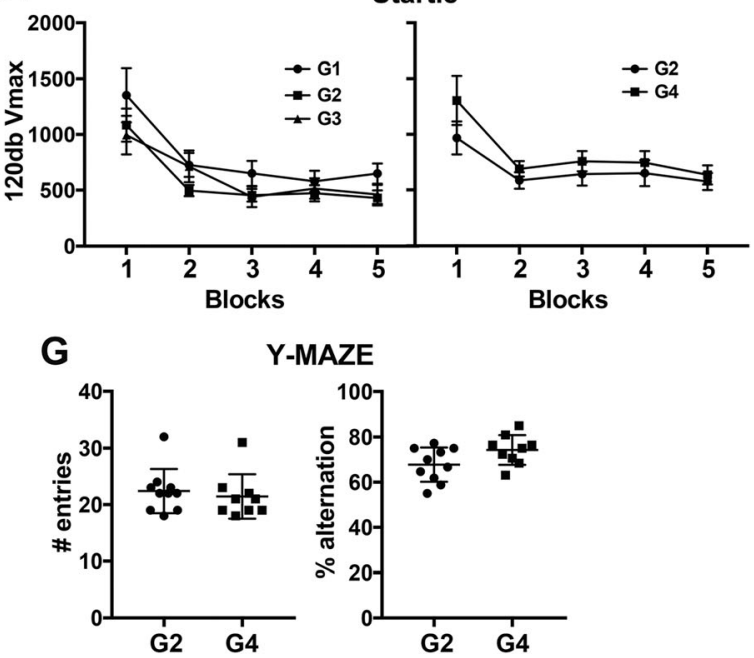

over days (G1: $n=13 ; \mathrm{G} 2: n=13 ; \mathrm{G} 3: n=14$; and G2: $n=16$, G4: $n=$ 14). (e) $120 \mathrm{~dB}$ startle amplitude (Vmax) over blocks of 5 trials and (f) percent inhibition of $120 \mathrm{~dB}$ response from pre-pulse stimulus intensities of 3, 6, 12, or $15 \mathrm{~dB}$ above background. (PND 61-63; G1: $n=18$, G2: $n=17 ; \mathrm{G} 3: n=21 ; \mathrm{G} 2: n=12, \mathrm{G} 4: n=14)$. (g) Y-maze number of entries and percent alternation at PND60 from G2 $(n=10)$ and G4 $(n=9)$. Drinking water exposure began on gestational day 6. Data represent means \pm SEM and individual animal responses. $* p<0.05$

statistical significance. In the femur, levels G2 were lower than all other groups $(p<0.001)$. While elevated, femur levels in the $10 \mathrm{ppm} \mathrm{F}^{-}$rats (G3) failed to reach statistical significance as compared to $\mathrm{G} 2(p=0.061)$. Femur levels in the $20 \mathrm{ppm} \mathrm{F}^{-}$group (G4) were significantly higher than G2 $(p<0.0001)$. In adult rats (Table 2), G2 had lower plasma $\mathrm{F}^{-}$ levels as compared to all other groups $(p<0.001)$. In the brain, 10 ppm $\mathrm{F}^{-}$did not significantly elevate $\mathrm{F}^{-}$levels over $\mathrm{G} 2$. Exposure to $20 \mathrm{ppm} \mathrm{F}^{-}$resulted in significantly higher levels of $\mathrm{F}^{-}$in the brain as compared to $\mathrm{G} 2(p<0.02)$. Accumulation of $\mathrm{F}^{-}$in the femur was lowest in $\mathrm{G} 2$ receiving low- $\mathrm{F}^{-}$chow as compared to G1 receiving standard chow $(p<0.001)$; G3 receiving $10 \mathrm{ppm} \mathrm{F}^{-}$(G3; $p<0.05$ ); or $\mathrm{G} 4$ receiving 20 ppm F $(p<0.0001)$. Urine levels were significantly elevated in $\mathrm{G} 4$ as compared to G2 $(p<0.001)$.

\section{T3, T4, and TSH Levels}

In adult rats, no differences were observed across groups for serum T3 or T4 levels (Table 3). As compared to G1 rats 
A

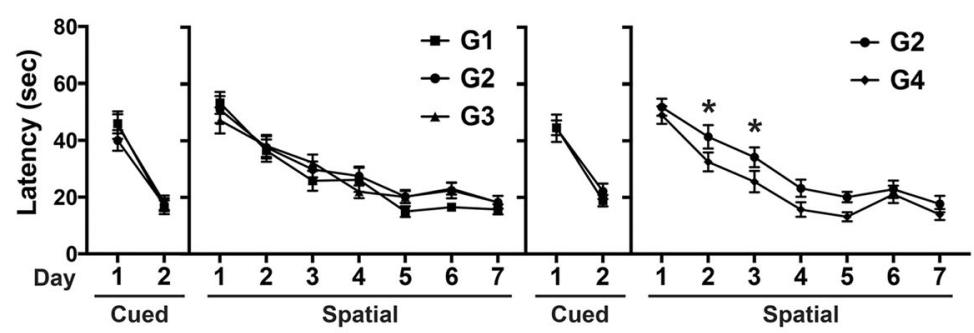

C
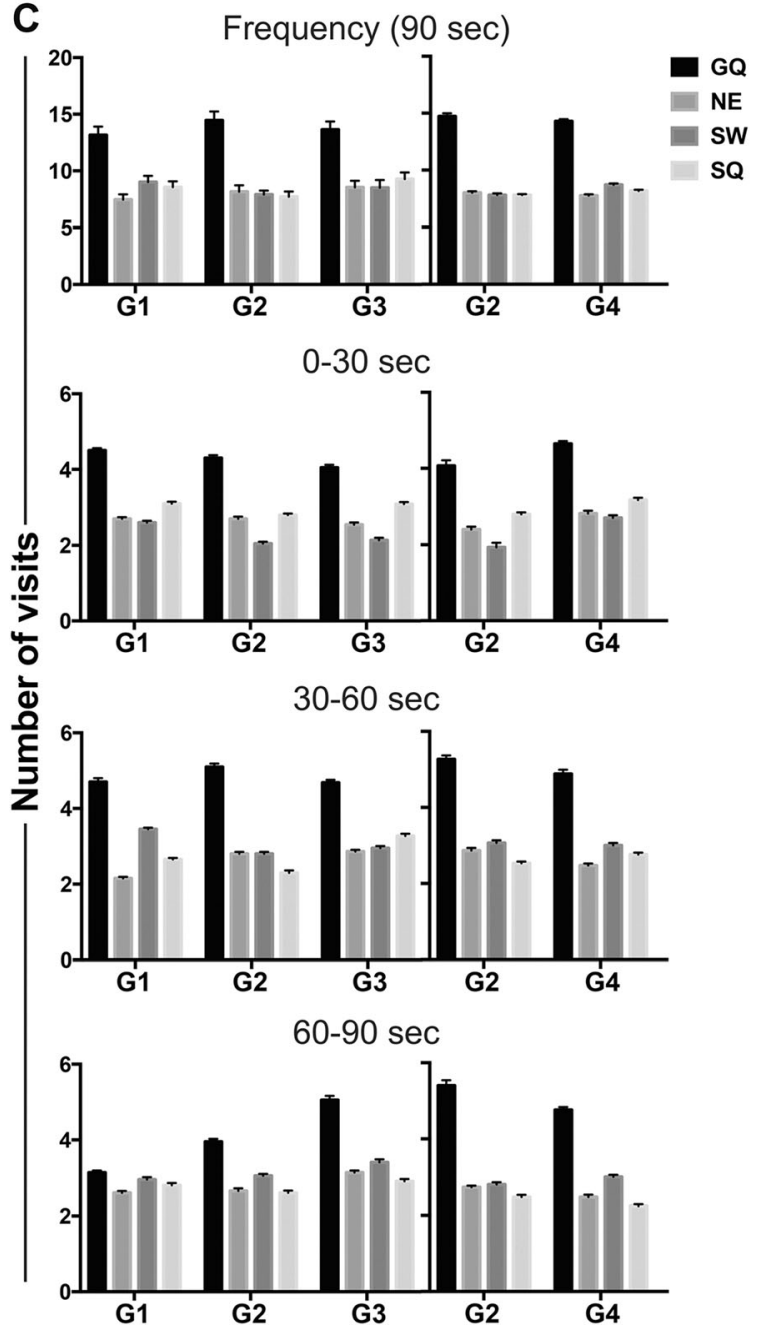

Fig. 4 Morris water maze performance in adult Long-Evans hooded male rats. (a) Cued learning across 2 days and spatial training across 7 days. Data expressed as mean latency \pm SEM (over three trials per day) to escape onto platform in the goal quadrant (GQ). A significant decrease in latency was observed over training (G1 vs. $\mathrm{G} 2$ : $\mathrm{F}_{(6,228)}=26.28 ; p<0.0001 ; \mathrm{G} 2$ vs. G3: $\mathrm{F}_{(6,240)}=20.81 ; p<0.0001 ; \mathrm{G} 2$ vs. G4: $\left.\mathrm{F}_{(6,180)}=32.07 ; p<0.0001\right)$. *significantly different $(p<0.01)$ as compared to G2. (b) Probe trial initial latencies to enter GQ or platform zone (PZ). (c-d) Probe trial distribution to quadrants

maintained on a standard chow diet, TSH levels were significantly lower in $\mathrm{G} 2$ rats maintained on low- $\mathrm{F}^{-}$chow $(p<0.001)$. No significant differences in TSH levels were observed across groups maintained on the low- $\mathrm{F}^{-}$chow as a function of $\mathrm{F}^{-}$in the drinking water (Table 3).
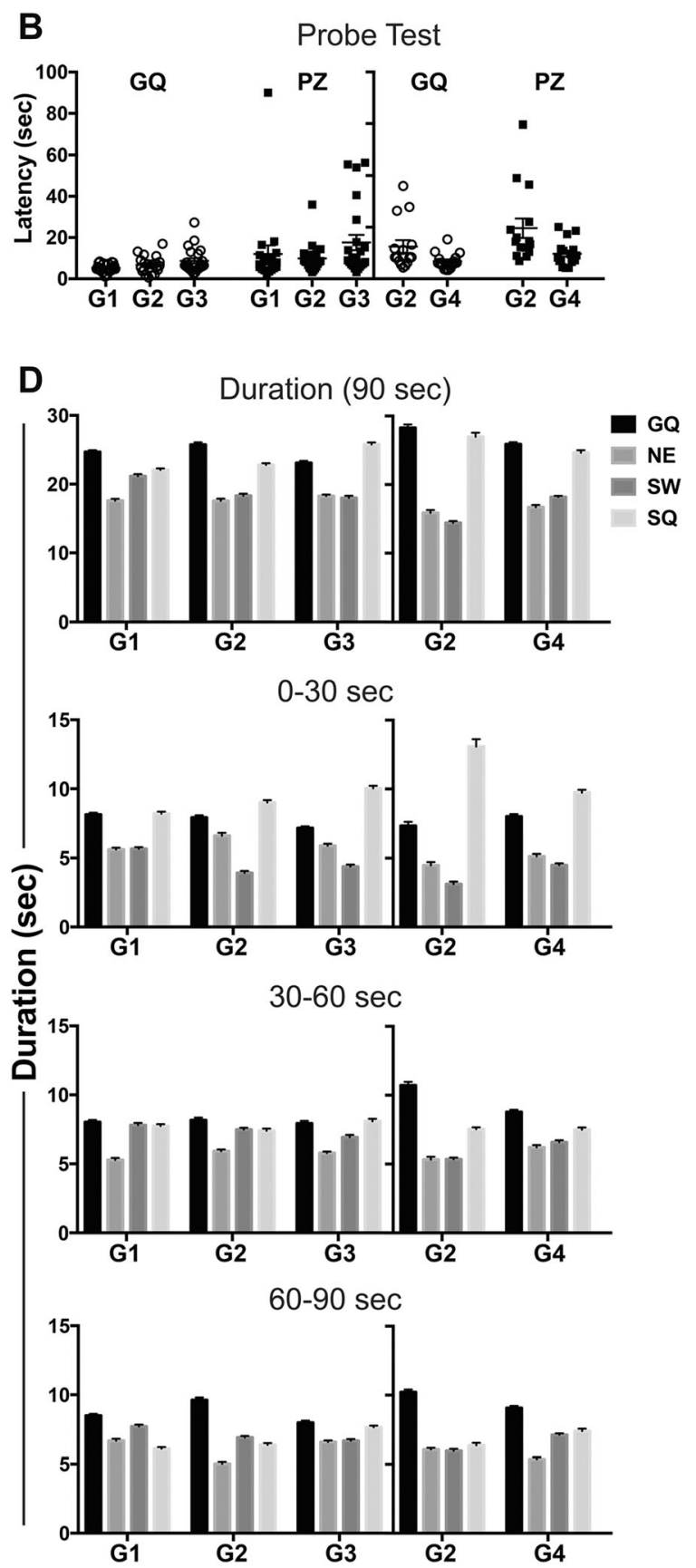

across 90- and 30-s epochs for (c) \# of visits and (d) duration of time in each quadrant. Data represents mean \pm SEM and individual animal responses. G1: standard chow/ RO- $\mathrm{H}_{2} \mathrm{O}(n=20) ; \mathrm{G} 2$ : low-F' chow/RO- $\mathrm{H}_{2} \mathrm{O}(n=20) ; \mathrm{G} 3$ : low-F $\mathrm{F}^{-}$chow $/ 10$ ppm F drinking water $(n=22)$ and $\mathrm{G} 2(n=15)$ and $\mathrm{G} 4$ : low-

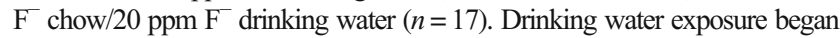
on gestational day 6. Distinctions of the individual quadrants: GQ: Northwest goal quadrant; NE, Northeast; SW, Southwest; SQ, Southeast start quadrant

\section{Histological Examination of the Brain}

A survey of H\&E, Nissl, and GFAP staining of the hippocampus did not detect evidence of neuronal death or morphological characteristics of glial reactivity normally 

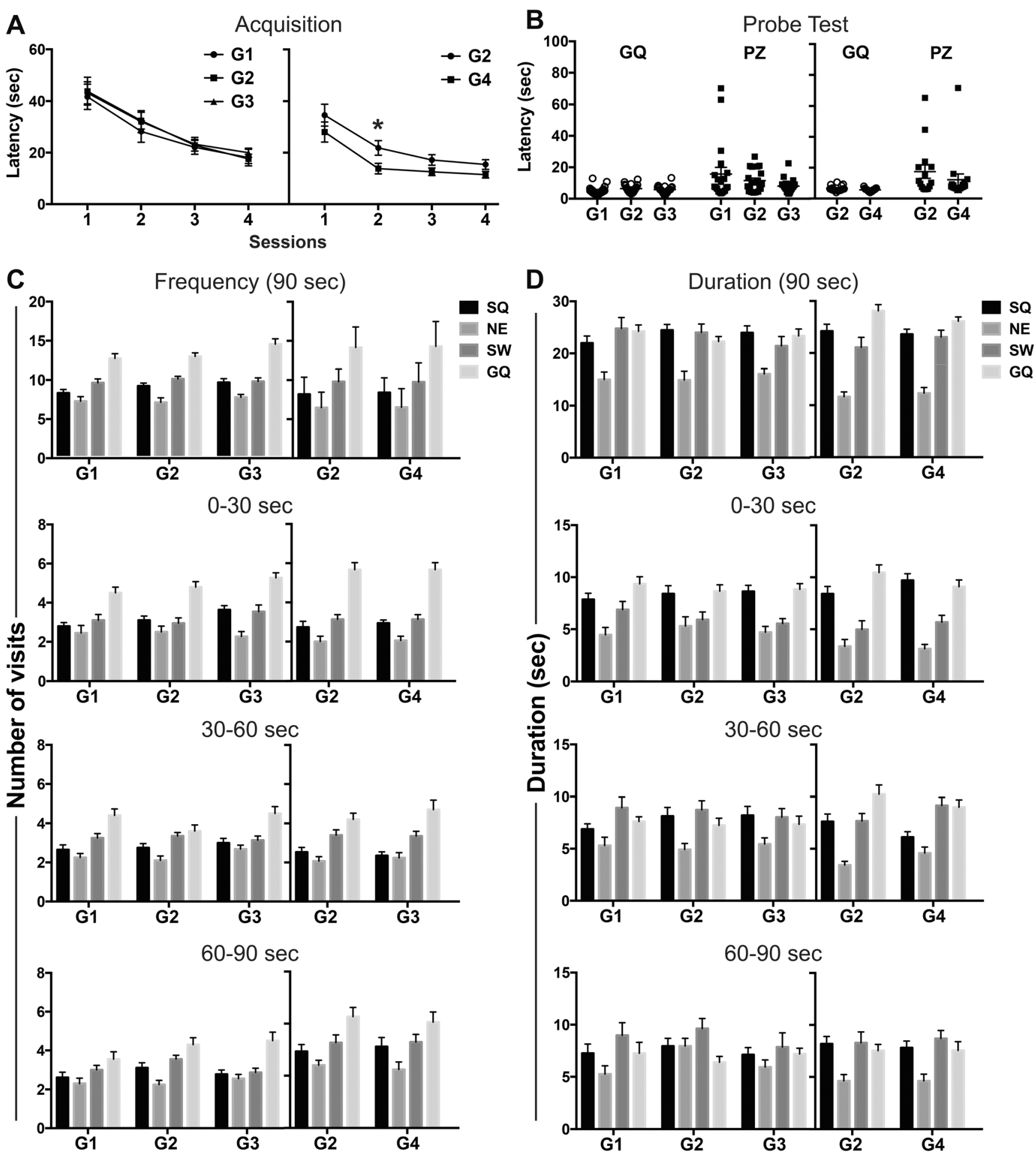

Fig. 5 Morris water maze reversal learning of adult Long-Evans hooded male rats. (a) Acquisition as measured by mean latency (three trials per day) \pm SEM to escape onto platform located in new goal quadrant (GQ). A significant decrease in latency was observed over training (G1 vs. G2: $\mathrm{F}_{(3,114)}$ $=16.85 ; p<0.0001 ; \mathrm{G} 2$ vs. $\mathrm{G} 3: \mathrm{F}_{(3,120)}=19.27 ; p<0.0001 ; \mathrm{G} 2$ vs. $\mathrm{G} 4: \mathrm{F}_{(3,90)}$ $=20.29 ; p<0.0001) . * p<0.01$ as compared to G2. (b) Probe trial initial latencies to enter GQ or platform zone (PZ). Probe trial distribution to

associated with brain injury. A relatively uniform distribution of GFAP+ astrocytes was observed. There was no

quadrants across 90- and 30-s epochs for (c) \# visits and (d) duration of time in each quadrant. Data represents mean $\pm \mathrm{SEM}$. G1: standard chow $/ \mathrm{RO}-\mathrm{H}_{2} \mathrm{O}$ $(n=20) ; \mathrm{G} 2$ : low- $\mathrm{F}^{-}$chow/RO- $\mathrm{H}_{2} \mathrm{O}(n=20) ; \mathrm{G} 3$ : low-F chow/10 ppm F drinking water $(n=22)$ and $\mathrm{G} 2(n=15)$ and $\mathrm{G} 4$ low-F $\mathrm{F}^{-}$chow/20 ppm Fdrinking water $(n=17)$. Drinking water exposure began on gestational day 6 . Distinction of the individual quadrants: GQ, Southeast goal quadrant; SW, Southwest; NE, Northeast; SQ, Northwest start quadrant

evidence of astrocyte hypertrophy in the suprapyramidal layer of the dentate gyrus and the CA1 pyramidal cell 
Table 2 Fluoride levels in Long-Evans hooded rats following drinking water exposure to fluoride

\begin{tabular}{llllll}
\hline Age & Sample & G1 & G2 & G3 (10 ppm $)$ & G4 (20 ppm) \\
\hline Weanling & Brain $(\mu \mathrm{g} / \mathrm{g})$ & $0.0253^{* *} \pm 0.01(n=6)$ & $0.00 \pm 0.0(n=6)$ & $0.0477^{* *} \pm 0.01(n=6)$ & $0.0811^{* *} \pm 0.04(n=6)$ \\
& Femur $(\mu \mathrm{g} / \mathrm{g})$ & $216.7^{* *} \pm 4.8(n=6)$ & $35.2 \pm 1.2(n=6)$ & $235.0^{\mathrm{b}} \pm 25.0(n=6)$ & $379.8^{* * * \pm 54.6(n=6)}$ \\
Adult & Plasma $(\mu \mathrm{g} / \mathrm{ml})$ & $0.018^{* * *} \pm 0.003(n=10)$ & $0.001 \pm 0.000(n=10)$ & $0.036^{* * *} \pm 0.010(n=8)$ & $0.025^{* * * \pm 0.005(n=10)}$ \\
& Urine $(\mu \mathrm{g} / \mathrm{ml})$ & & $0.59 \pm 0.14(n=8)$ & & $4.99 * * \pm 0.96(n=8)$ \\
& Brain $(\mu \mathrm{g} / \mathrm{g})$ & $0.35 \pm 0.14(n=10)$ & $0.21 \pm 0.08(n=10)$ & $0.27 \pm 0.11(n=8)$ & $0.85^{*} \pm 0.24(n=10)$ \\
& Femur $(\mu \mathrm{g} / \mathrm{g})$ & $541.6^{* * *} \pm 13.6(n=10)$ & $56.79^{\mathrm{a}} \pm 2.1(n=8)$ & $681.2^{*} \pm 43.8(n=10)$ & $993.4 * * * 95.2(n=10)$ \\
\hline
\end{tabular}

Data represents mean \pm SEM

Rats were exposed from gestational day 6 to tissue collection

G1: standard chow (Teklad 2918)/RO- $\mathrm{H}_{2} \mathrm{O}$

G2: low-F chow (Teklad TD.160173)/RO- $\mathrm{H}_{2} \mathrm{O}$

G3: low-F chow (Teklad TD.160173)/10 ppm F $\mathrm{F}^{-}$drinking water

G4: low-F chow (Teklad TD.160173)/20 ppm F- drinking water

${ }^{\mathrm{b}} p=0.06, * p<0.05, * * p<0.01, * * * p<0.001$ as compared to $\mathrm{G} 2$

${ }^{\mathrm{a}}$ Two outliers excluded $(276.8$ and $849.0 \mu \mathrm{g} / \mathrm{g})$

layer (Fig. 6). Iba-1 staining for microglia showed a relatively uniform distribution of process-bearing cells in the hippocampus with no evidence of hypertrophy or amoeboid morphology (Fig. 7).

\section{Pathology}

A general pathology examination was conducted on the heart, kidney, liver, testes, epididymides, prostate, and seminal vesicles (Supplementary Table S2). For the heart, kidney, liver, or testes, no differences were recorded for weight and no exposure-related pathology was observed. No $\mathrm{F}^{-}$-related changes were observed in the seminal vesicles or epididymides and there was no apparent decrease in the density or quantity of sperm within the epididymal tubules. In the $20 \mathrm{ppm} \mathrm{F}^{-}$ group, an increase in incidence (7/13 vs. 2/10) was observed for mild to moderate chronic inflammation in the prostate gland. Infiltration of mononuclear inflammatory cells within the interstitium was observed associated with concretions within affected glands (Fig. 8).

\section{Discussion}

Male rat offspring maintained on a low $-\mathrm{F}^{-}$chow and exposed to 10 or $20 \mathrm{ppm} \mathrm{F}^{-}$in the drinking water beginning on GD6 showed a significantly elevated internal $\mathrm{F}^{-}$burden in the weanling brain and femur as compared to levels observed in the low- $\mathrm{F}^{-}$chow and normal drinking water. Deposition continued into adulthood. Drinking water exposure at these low levels was not found to alter motor performance or learning and memory in the test paradigms assessed. Low-level $\mathrm{F}^{-}$did not alter thyroid hormone levels and produce neuronal damage or glia reactivity in the hippocampus, or histological damage in the heart, kidney, or liver. The low-level $\mathrm{F}^{-}$diet did not show a significant effect on the behavioral endpoints

Table 3 T3, T4, and TSH levels in Long-Evans Hooded rats following drinking water exposure to fluoride

\begin{tabular}{lllll}
\hline & $\mathrm{G} 1$ & $\mathrm{G} 2$ & $\mathrm{G} 3(10 \mathrm{ppm})$ & $\mathrm{G} 4(20 \mathrm{ppm})$ \\
\hline $\mathrm{T} 3(\mathrm{ng} / \mathrm{dl})$ & $153.80 \pm 5.74(n=6)$ & $137.80 \pm 6.49(n=6)$ & $143.20 \pm 8.43(n=6)$ & $148.00 \pm 4.82(n=6)$ \\
T4 $(\mu \mathrm{g} / \mathrm{dl})$ & $6.86 \pm 0.36(n=6)$ & $7.03 \pm 0.34(n=6)$ & $6.35 \pm 0.59(n=6)$ & $6.70 \pm 0.23(n=6)$ \\
TSH $(\mathrm{ng} / \mathrm{ml})$ & $18.93 * * \pm 5.70(n=6)$ & $2.83 \pm 0.44(n=6)$ & $2.65 \pm 0.53(n=6)$ & $2.35 \pm 0.61(n=6)$ \\
\hline
\end{tabular}

Data represents mean \pm SEM

Rats were exposed from gestational day 6

G1: standard chow (Teklad 2918)/RO- $\mathrm{H}_{2} \mathrm{O}$

G2: low-F ${ }^{-}$chow (Teklad TD.160173)/RO- $\mathrm{H}_{2} \mathrm{O}$

G3: low-F $\mathrm{F}^{-}$chow (Teklad TD.160173)/10 ppm F $\mathrm{F}^{-}$drinking water

G4: low-F $\mathrm{F}^{-}$chow (Teklad TD.160173)/20 ppm F $\mathrm{F}^{-}$drinking water

$* * p<0.01$ as compared to $\mathrm{G} 2$ 
Fig. 6 Representative images of GFAP+ astrocytes in the hippocampus of adult LongEvans hooded male rats exposed to low- $\mathrm{F}^{-}$chow/RO- $\mathrm{H}_{2} \mathrm{O}$ or low$\mathrm{F}^{-}$chow $/ 20$ ppm $\mathrm{F}^{-}$drinking water beginning on gestational day 6. (a) Suprapyramidal blade of the dentate gyrus. (b) CA1 pyramidal cell layer. Cells displayed normal process-bearing morphology with no evidence of hypertrophy. 3,3-

diaminobenzidine staining (brown). Hematoxylin counterstain (blue) showed no disruption of the normal morphology of the hippocampal regions and no evidence of neuronal death. $(n=6)$. Scale bar $=100 \mu \mathrm{m}$

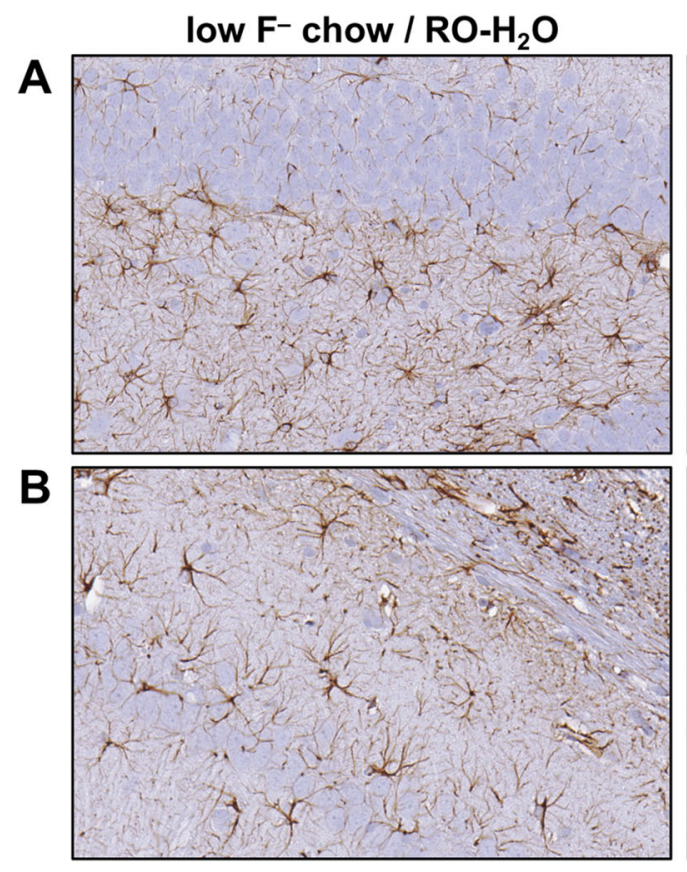

low F- chow / 20ppm F-
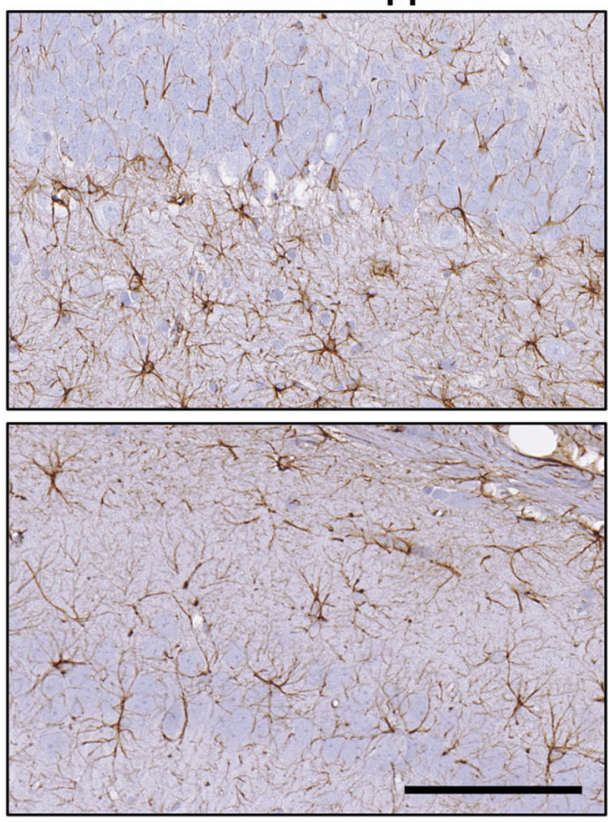

examined. Effects observed at the $20 \mathrm{ppm} \mathrm{F}^{-}$drinking water level included mild hyperanalgesia and an inflammatory response in the prostate.

Fluoride exposure occurs from multiple sources, yet the majority of studies reporting effects of fluoride on the nervous system were not often supported by analytical confirmation of exposure or consideration of contributions from drinking water source or chow. When reported, control water ranged from 0.15 to $1.77 \mathrm{ppm} \mathrm{F}^{-}$and rodent chow between 10 and $25 \mathrm{ppm}$ $\mathrm{F}^{-}$(NTP 2016). Estimates of internal exposures have relied heavily on serum/plasma levels with limited studies providing data on urine excretion or deposition and accumulation in the bone or brain (Table 4; NTP 2016). Fluoride is rapidly absorbed from the gastrointestinal tract with transient peak plasma concentrations of approximate $30 \mathrm{~min}$ half-life. From the blood, $\mathrm{F}^{-}$crosses the placenta (Shen and Taves 1974; Gui et al. 2010), less so into breast milk (Shen and Taves 1974; Ekstrand et al. 1981), and the blood-brain-barrier reduces entry into the brain (Whitford 1996). Calcified tissues such as the bone and teeth readily incorporate fluoride (NRC 2006) most prominently during periods of rapid growth and represent approximately $99 \%$ of the body burden of $\mathrm{F}^{-}$that is not
Fig. 7 Representative images of Iba-1+ microglia in the hippocampus of adult LongEvans hooded rats exposed to low- $\mathrm{F}^{-}$chow/ $\mathrm{RO}-\mathrm{H}_{2} \mathrm{O}$ or low- $\mathrm{F}^{-}$ chow $/ 20$ ppm $\mathrm{F}^{-}$drinking water beginning on gestational day 6 . (a) Suprapyramidal blade of the dentate gyrus. (b) CA1 pyramidal cell layer. Cells displayed normal process-bearing morphology with no evidence of reactivity or activation. 3,3-diaminobenzidine staining (brown). Hematoxylin counterstain (blue) $(n=6)$. Scale bar $=100 \mu \mathrm{m}$

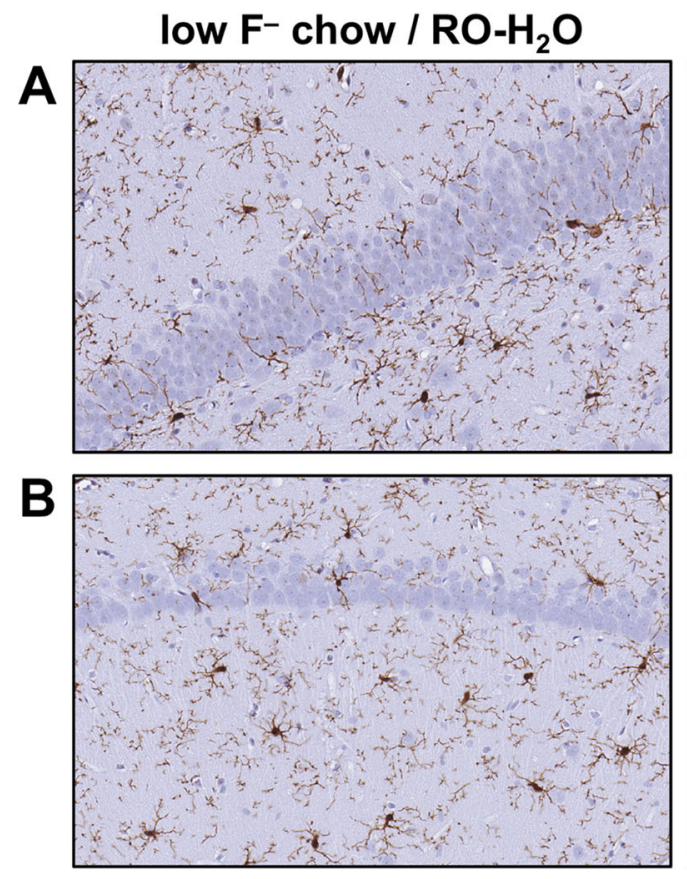

low F- chow / 20ppm F-
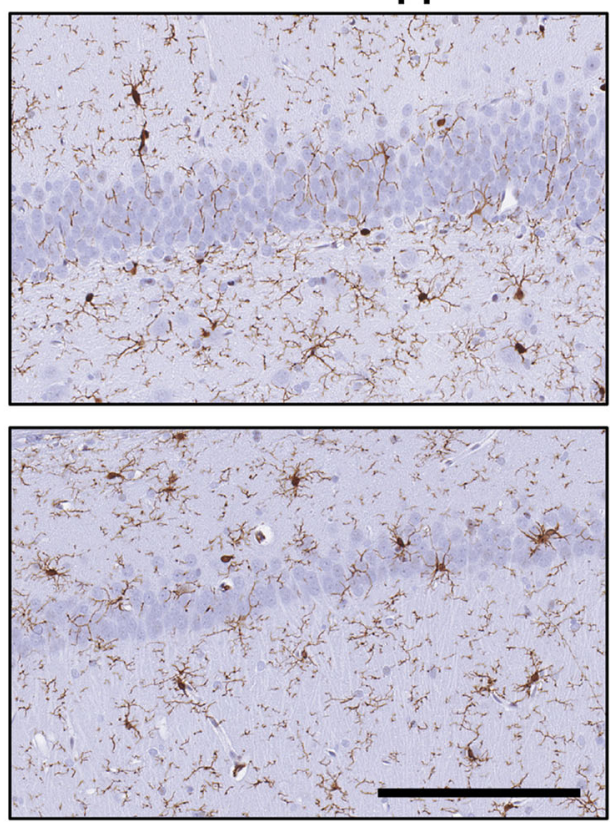


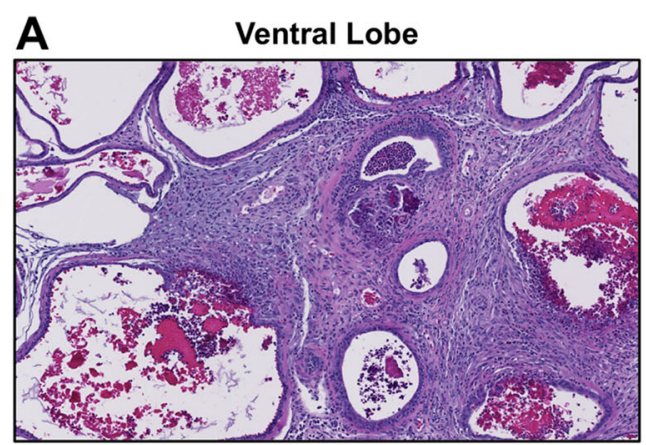

Fig. 8 Representative images of prostate from adult male rats receiving to (G2) low- $\mathrm{F}^{-}$chow/RO- $\mathrm{H}_{2} \mathrm{O}$ or (G4) low- $\mathrm{F}^{-}$chow/RO- $\mathrm{H}_{2} \mathrm{O} 20$ ppm F drinking water beginning on gestational day 6 . Chronic inflammation is evident as dense infiltrating immune cells in the (a) ventral and (b) dorsal lobes with infiltration of mononuclear cells, expansion of interstitium, and concretions within the glandular lumen. Hematoxylin and eosin

rapidly excreted by the urine (Kaminsky et al. 1990; Hamilton 1992; Whitford 1996). In humans, the average bone concentration is linearly related to water concentration and duration of exposure (Jackson and Weidmann 1958; Zipkin et al. 1958; Arnala et al. 1986; Rao et al. 1995). In rodents, $F^{-}$also accumulates in the bone (Rumiantsev et al. 1988; Bucher et al. 1991; de Carvalho et al. 2006; Gui et al. 2010; Dong et al. 2015a) increasing over age and exposure (Zipkin and McClure 1952; Ekstrand et al. 1994; Dunipace et al. 1995; Whitford 1999). In the current study, developmental exposure elevated $\mathrm{F}^{-}$levels in the femur and brain at PND25 with continued deposition with age to levels comparable to previous studies (Table 4). A contribution from $\mathrm{F}^{-}$in chow was also observed in the femur and brain and a differential absorption between water and food was demonstrated. With the standard chow, femur levels similar to that reported by de Carvalho et al. (2006) following $20 \mathrm{~g} \mathrm{~F}^{-} / \mathrm{g}$ chow but lower than levels observed with $20 \mathrm{ppm} \mathrm{F}^{-}$in the drinking water.

Many studies that examined effects of $\mathrm{F}^{-}$exposure on learning and memory have relied on avoidance conditioning or maze performance. Such assessments can be influenced by activity level or motor deficits thus, requiring testing paradigms to address such confounders. Using an operant conditioning paradigm not dependent upon motor activity, Whitford et al. (2009) reported no learning deficit in rats exposed to $\mathrm{F}^{-}(10-50 \mathrm{ppm})$. Previous studies using a step-down avoidance procedure reported a deficit in rodents exposed to $\mathrm{F}^{-}$(45-50 ppm) (Wang et al. 2004; Wu et al. 2006). In the current study, performance on a similar step-through passive avoidance task identified no exposure-related differences in learning. No differences were observed in light/dark place preference or pain perception that could have influenced PA performance. A slight thermal hyperanalgesia was observed in rats exposed to $20 \mathrm{ppm} \mathrm{F}^{-}$. This is consistent with thermal hyperalgesia and mechanical allodynia in rats exposed to 75 ppm $\mathrm{F}^{-}$reported by Balayssac et al. (2002) but not with hypoanalgesia observed in rats exposed to $25 \mathrm{ppm} \mathrm{F}^{-}(\mathrm{Wu}$

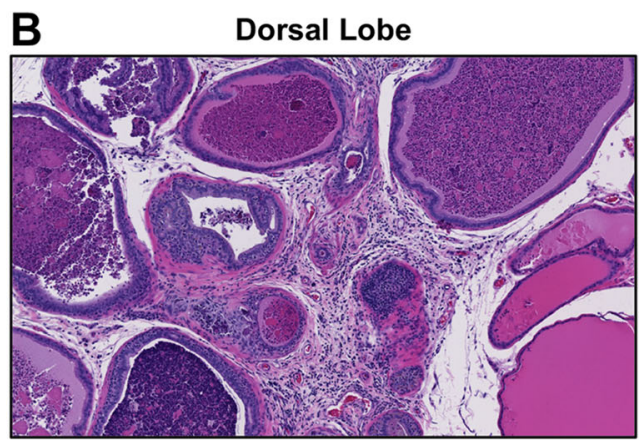

staining. A higher incidence of prostate inflammation was observed in $\mathrm{G} 4$ receiving low- $\mathrm{F}^{-}$chow/20 $\mathrm{ppm} \mathrm{F}^{-}$(7 out of 13) as compared to G1 receiving standard chow $/ \mathrm{RO}-\mathrm{H}_{2} \mathrm{O}$ (0 out of 11$), \mathrm{G} 2$ receiving low- $\mathrm{F}^{-}$ chow/RO- $\mathrm{H}_{2} \mathrm{O}$ (2 out of 6 ), or $\mathrm{G} 3$ receiving low- $\mathrm{F}^{-}$chow/ 10 ppm $\mathrm{F}^{-}$ ( 0 out of 8$)$ drinking water

et al. 2008). As early as 1967, Elliott reported an absence of effect on maze performance following 4 weeks of exposure to $42.4 \mathrm{ppm} \mathrm{F}^{-}$. Using a food-reinforced maze task, Shalini and Sharma (2015) found no differences in errors but reported a longer latency on the first the first daily training trials over the first 2 weeks as a learning deficit in rats exposed to $10 \mathrm{ppm} \mathrm{F}^{-}$. The limited and transient nature of the response suggests a deficit in motor function rather than learning. Using different paradigms to assess learning and memory, the current study did not identify performance differences in rats exposed to $\leq$ 20 ppm $\mathrm{F}^{-}$drinking water. No exposure-related differences were observed in Y-maze alternation rate, consistent with findings of Li et al. (2015). In studies using the MWM, a longer latency or greater distance traveled to the platform during the acquisition phase has been reported (Wu et al. 2008; Jiang et al. 2014b; Wei et al. 2014; Dong et al. 2015b). When acquisition data was reported, learning in exposed rats was demonstrated by a decrease in latency with training (Wu et al. 2008; Gui et al. 2010). In the few studies that included a MWM probe test, rats exposed to $\mathrm{F}^{-}$in the chow (104 ppm; Gui et al. 2010) or drinking water (50 ppm; Dong et al. 2015b) showed deficits in isolated measures but preference for the escape quadrant was not reported. To address some of these limitations, the current study included recommendations of Vorhees and Williams (2006) and examined a number of aspects of the MWM performance including the sensitive measures of the number of visits and preference for goal quadrant over epochs. Using this approach, we did not observe differences in learning the MWM task, memory of the escape location, or ability to learn a new escape location.

In vitro studies have suggested a detrimental effect of fluoride exposure on neurons however, these effects occur at dose levels outside of the expected in vivo range of ppb (Table 4) (Zhang et al. 2008 (10-40 ppm); Lee et al. 2016 (5 mM NaF; $89 \mathrm{ppm}^{-}$); Inkielewicz-Stepniak et al. 2012; 1.9 and $4.75 \mathrm{ppm} \mathrm{F}^{-}$). For in vivo exposure, neuronal death or dysfunction was observed in the rat hippocampus (Basha et al. 
Table 4 Summary of selected publications of fluoride levels in rats following fluoride exposure

\begin{tabular}{|c|c|c|c|c|c|c|c|c|c|}
\hline Study & $\begin{array}{l}\text { Rat } \\
\text { strain }\end{array}$ & Age $(n)$ & $\begin{array}{l}\text { Fluoride } \\
(\mathrm{ppm})\end{array}$ & Route & Duration & Brain $[\mu \mathrm{g} / \mathrm{g}]^{\mathrm{a}}$ & $\begin{array}{l}\text { Serum/plasma } \\
{[\mu \mathrm{g} / \mathrm{ml}]^{\mathrm{b}}}\end{array}$ & $\begin{array}{l}\text { Urine } \\
{[\mu \mathrm{g} / \mathrm{ml}]^{\mathrm{a}}}\end{array}$ & $\begin{array}{l}\text { Bone } \\
{[\mu \mathrm{g} / \mathrm{g}]^{\mathrm{b}}}\end{array}$ \\
\hline \multicolumn{10}{|l|}{ Adult exposure } \\
\hline $\begin{array}{l}\text { Balayssac et al. } \\
\qquad 2002^{\mathrm{c}}\end{array}$ & $\mathrm{SD}$ & Adult $(10 \stackrel{\jmath}{\text { ○े }})$ & $0,75,150$ & DW & 104 days & & $1,5.5,10.9 \mu \mathrm{m}$ & & \\
\hline $\begin{array}{l}\text { de Carvalho et al. } \\
2006\end{array}$ & Wistar & Adult $\left(10{ }^{\lambda}\right)$ & $0,5,15,50$ & DW & 120 days & & $\begin{array}{l}0.03,0.048 \\
0.115,0.187\end{array}$ & & $\begin{array}{l}647,808 \\
1414,3439\end{array}$ \\
\hline Dong et al. 2015a & $\mathrm{SD}$ & Adult (30^우) & $0.23,22.6$ & DW & 10 months & & & $1.7,2.16$ & $1.52,2.31$ \\
\hline $\begin{array}{l}\text { Ekambaram and } \\
\text { Paul } 2001\end{array}$ & Wistar & Adult (8ㅇ) & $0,226.24$ & DW & 60 days & & $0.22,1.94$ & & \\
\hline Gao et al. $2009 \mathrm{a}$ & SD & Adult (8 $\left.\jmath^{\lambda}+\right)$ & $\begin{array}{l}0.23,2.26 \\
226\end{array}$ & DW & 6 months & & & $\begin{array}{l}1.02,2.59 \\
5.96\end{array}$ & $\begin{array}{c}669.4,1135.2 \\
1304.3\end{array}$ \\
\hline Gao et al. $2009 b$ & SD & Adult (8 $\overbrace{}^{\lambda}+$ ) & $0,62.68$ & Gavage & 3 months & & $0.018,7.135$ & $\begin{array}{l}1.462 \\
64.966\end{array}$ & \\
\hline Jiang et al. 2014a & SD & Adult (8 ठ) & $0,54.3$ & DW & 3 months & $0.25,1.19$ CTX & $0.09,0.4$ & & \\
\hline Li et al. 2015 & Wistar & $\begin{array}{l}\text { Juvenile-adult } \\
\quad(10 \overbrace{}^{\lambda})\end{array}$ & $0,22.6$ & DW & 3 months & & & $6.67,22.5$ & $0.0646,0.189$ \\
\hline $\begin{array}{l}\text { Lombarte et al. } \\
\quad 2013\end{array}$ & SD & Adult (10ㅇ) & 0,15 & DW & 1 month & & $2.28,2.85$ & & \\
\hline $\begin{array}{l}\text { Mullenix et al. } \\
1995\end{array}$ & $\mathrm{SD}$ & Adult (20 ㅇ) & $0,45.3$ & DW & 6 weeks & $\begin{array}{l}0.406,0.252 \mathrm{BG} \\
0.358,0.325 \mathrm{CB} \\
0.479,0.602 \mathrm{CTX} \\
0.258,0.79 \mathrm{HC} \\
0.396, \\
0.308 \mathrm{HT} 0.634, \\
0.306 \mathrm{MB}\end{array}$ & $0.01,0.077$ & & \\
\hline $\begin{array}{l}\text { Rogalska et al. } \\
2017\end{array}$ & Wistar & Adult $(8 \widehat{\partial},+9)$ & $0,4.5,22.6$ & DW & 4 weeks & & $\begin{array}{l}0.0541,0.0596 \\
\quad 0.0823\end{array}$ & & \\
\hline $\begin{array}{l}\text { Rumiantsev et al. } \\
1988^{\mathrm{c}}\end{array}$ & Rat & Adult & $0,33.32$ & Gavage & 30 days & & & $14,744 \mathrm{pg}$ & $\begin{array}{l}2.3,10.6 \\
\text { mg\% thigh } \\
\text { bone }\end{array}$ \\
\hline $\begin{array}{l}\text { Shalini and } \\
\text { Sharma } 2015\end{array}$ & Wistar & Adult $(10 \stackrel{0}{0})$ & $.9,10$ & DW & 2 months & $0.55,2.61$ & $.048, .06$ & & \\
\hline $\begin{array}{l}\text { Whitford et al. } \\
2009\end{array}$ & $\mathrm{SD}$ & Adult $(8+$ ) & $\begin{array}{c}0,33.285 .6 \\
155.2\end{array}$ & DW & 8 months & $\begin{array}{r}0.082,3.9,6.42 \\
18.1 \mu \mathrm{mol} / \mathrm{kg}\end{array}$ & $\begin{array}{l}0.32,15.27 \\
25.72, \\
97.56 \mu \mathrm{mol} / \mathrm{L}\end{array}$ & & $\begin{array}{c}150,5408 \\
9497 \\
14,847\end{array}$ \\
\hline \multicolumn{10}{|c|}{ Developmental exposure } \\
\hline Banji et al. 2013 & Wistar & $\operatorname{Dam}(6$ 우 & $\begin{array}{l}0,20 \mathrm{mg} / \mathrm{kg} \\
\mathrm{NaF}\end{array}$ & Gavage & GD6-PND11 & & $\begin{array}{l}\text { Dams } 0.12,0.32 \\
\text { Pups } 0.14, \\
0.42\end{array}$ & & \\
\hline Basha et al. 2011 & Wistar & $\operatorname{Dam}(8+)$ & $0,100,200$ & DW & GD0-3 months & $\begin{array}{l}0.318,1.83,2.32 \mathrm{CB} \\
0.672,2.28,3.43 \\
\text { CC } \\
0.258,0.993,1.93 \\
\text { HC } 0.358,2.12, \\
3.09 \mathrm{MO}\end{array}$ & & & \\
\hline $\begin{array}{l}\text { Dong Dong et al. } \\
2015 \mathrm{~b}\end{array}$ & $\mathrm{SD}$ & $\begin{array}{l}\text { Dams } \\
\quad 10 \text { months } \\
\text { (30우 })\end{array}$ & 0,50 & DW & $\begin{array}{l}\text { GD0-PND30 } \\
\text { (10) }\end{array}$ & & & $1.7,2.16$ & 35,211 \\
\hline Gui et al. $2010^{c}$ & SD & $\begin{array}{l}\text { Dams } \\
6 \text { months } \\
(6+9)\end{array}$ & $\begin{array}{c}6.2,104 \\
\mathrm{mg} / \mathrm{kg} \\
\mathrm{NaF}\end{array}$ & Food & $\begin{array}{l}\text { GD0-PND30 } \\
\text { (10) }\end{array}$ & $\begin{array}{l}6.2 \text { and } 104 \\
\mathrm{mg} / \mathrm{kg} \mathrm{NaF}\end{array}$ & & $0.98,8.52$ & 1124,1873 \\
\hline
\end{tabular}

${ }^{\mathrm{a}}$ Values represent total $\mathrm{F}^{-} \mathrm{pg} / \mathrm{g}(\mathrm{ppm})$ unless otherwise noted

${ }^{\mathrm{b}}$ Values represent total $\mathrm{F}^{-} \mathrm{pg} / \mathrm{ml}$ (ppm) unless otherwise noted

${ }^{\mathrm{c}}$ Values presented as in publication

$D W$, drinking water; $B G$, basal ganglia; $C C$, cerebral cortex; $C B$, cerebellum; $C T X$, cortex; $H C$, hippocampus; $H T$, hypothalamus; $M B$, midbrain; $M O$, medulla oblongata

2011; Shashi and Kumar 2016; Shivarajashankara et al. 2002; Yan et al. 2016; Teng et al. 2017) and neuronal shrinkage in the frontal cortex (Akinrinade et al. 2015). In the current study, hippocampal neurons displayed a normal morphology with no evidence of neuronal death. Neuronal death is normally accompanied by glia activation. Limited studies reported a stimulation of microlgia following $\mathrm{F}^{-}$exposure (Shuhua et al. 2012; Yan et al. 2013, 2016). In the current study, consistent with the absence of neuronal death, astrocytes and microglia retained a normal process-bearing morphology and showed no evidence of hypertrophy or activation. There are a number of experimental factors that could account for the 
differences in neuropathology findings between studies including differences in $\mathrm{F}^{-}$levels in chow and water source, as well as, potential processing artifacts for neuronal death (e.g., dark neurons, Zsombok et al. 2005; Jortner 2006).

At high exposure levels, fluoride exposure results in adverse effects on health. How this may reflect a specificity of effect on the nervous system or translates to lower exposure levels remains an important question. In many reports in the literature, the limited assessment across functional modalities and the over reliance on single terminal measures of performance such as, latency in the absence of an assessment of learning via demonstration of acquisition, limit the ability to evaluate a specific effect of $\mathrm{F}^{-}$on learning and memory. A direct comparison of our findings to those in the literature is limited primarily by a lack of information on such details as analytical data for exposure, water source, and rodent chow type/brand, as well as, limited endpoints and details of behavioral assessments. Addressing such issues in future studies will enhance the ability to compare findings across studies and allow for a better assessment of the neurotoxicity associated with fluoride as it relates to level of exposure.

Acknowledgements This research was supported by the Division of the National Toxicology Program, National Institute of Environmental Health Sciences, National Institutes of Health, Department of Health and Human Services no. 1Z01ES101623; ES021164, contract no. HHSN273201600011; HHSN273201500012C. We thank Dr. Manish Arora, Icahn School of Medicine at Mount Sinai for the assistance in evaluating fluorosis and for the assistance received from NIEHS histology core facility and Comparative Medicine Branch. Fluoride analysis was conducted by Indiana University Oral Health Research Institute.

Author Contribution C. Picut and A. Brix conducted the pathology review, G. Zhang conducted the statistical analysis, R. Wilson and S. Brar conducted the TH analysis and R. Gilliam assisted with the behavioral testing. C. McPherson and G.J. Harry contributed to the design and conduct of experiments, data analysis, and interpretation, and preparation of the manuscript.

\section{Compliance with Ethical Standards}

Conflict of Interest The authors declare that they have no conflict of interest.

Open Access This article is distributed under the terms of the Creative Commons Attribution 4.0 International License (http:// creativecommons.org/licenses/by/4.0/), which permits unrestricted use, distribution, and reproduction in any medium, provided you give appropriate credit to the original author(s) and the source, provide a link to the Creative Commons license, and indicate if changes were made.

\section{References}

Akinrinade ID, Memudu AE, Ogundele OM (2015) Fluoride and aluminium disturb neuronal morphology, transport functions, cholinesterase, lysosomal and cell cycle activities. Pathophysiology 22(2):105-115

Arnala I, Alhava EM, Kivivyuori R, Kauranen P (1986) Hip fracture incidence not affected by fluoridation. Osteofluorosis studied in
Finland. Acta Orthop Scand 57(4):344-348. https://doi.org/10. 3109/17453678608994408

Balaji B, Kumar EP, Kumar A (2015) Evaluation of standardized Bacopa monniera extract in sodium fluoride-induced behavioural, biochemical, and histopathological alterations in mice. Toxicol Ind Health 31(1):18-31. https://doi.org/10.1177/0748233712468018

Balayssac D, Richard D, Authier N, Nicolay A, Jourdan D, Eschalier A, Coudore F (2002) Absence of painful neuropathy after chronic oral fluoride intake in Sprague-Dawley and Lou/C rats. Neurosci Lett 327(3):169-172. https://doi.org/10.1016/S0304-3940(02)00421-4

Banji D, Banji OJ, Pratusha NG, Annamalai AR (2013) Investigation on the role of Spirulina platensis in ameliorating behavioural changes, thyroid dysfunction and oxidative stress in offspring of pregnant rats exposed to fluoride. Food Chem 140(1-2):321-331. https://doi.org/ 10.1016/j.foodchem.2013.02.076

Bartos M, Gumilar F, Bras C, Gallegos CE, Giannuzzi L, Cancela LM, Minetti A (2015) Neurobehavioural effects of exposure to fluoride in the earliest stages of rat development. Physiol Behav 147:205212. https://doi.org/10.1016/j.physbeh.2015.04.044

Basha PM, Sujitha NS (2012) Combined impact of exercise and temperature in learning and memory performance of fluoride toxicated rats. Biol Trace Elem Res 150(1-3):306-313. https://doi.org/10.1007/ s12011-012-9489-3

Basha PM, Rai P, Begum S (2011) Fluoride toxicity and status of serum thyroid hormones, brain histopathology, and learning memory in rats: a multigenerational assessment. Biol Trace Elem Res 144(13):1083-1094. https://doi.org/10.1007/s12011-011-9137-3

Bashash M, Thomas D, Hu H, Martinez-Mier EA, Sanchez BN, Basu N, Peterson KE, Ettinger AS, Wright R, Zhang Z, Liu Y, Schnaas L, Mercado-García A, Téllez-Rojo MM, Hernández-Avila M (2017) Prenatal fluoride exposure and cognitive outcomes in children at 4 and 6-12 years of age in Mexico. Environ Health Perspect 125(9): 097017. https://doi.org/10.1289/EHP655

Bera I, Sabatini R, Auteri P, Flace P, Sisto G, Montagnani M, Potenza MA, Marasciulo FL, Carratu MR, Coluccia A, Borracci P, Tarullo A, Cagiano R (2007) Neurofunctional effects of developmental sodium fluoride exposure in rats. Eur Rev Med Pharmacol Sci 11(4):211-224

Blokland A, Geraerts E, Been M (2004) A detailed analysis of rats' spatial memory in a probe trial of a Morris task. Behav Brain Res 154(1): 71-75. https://doi.org/10.1016/j.bbr.2004.01.022

Bucher JR, Hejtmancik MR, Toft JD, Persing RL, Eustis SL, Haseman JK (1991) Results and conclusions of the National Toxicology Program's rodent carcinogenicity studies with sodium fluoride. Int J Cancer 48(5):733-737. https://doi.org/10.1002/ijc.2910480517

Catani DB, Tenuta LMA, Andalo FA, Cury JA (2010) Fluorosis in rats exposed to oscillating chronic fluoride doses. Braz Dent J 21(1):3237. https://doi.org/10.1590/S0103-64402010000100005

Choi AL, Sun GF, Zhang Y, Grandjean P (2012) Developmental fluoride neurotoxicity: a systematic review and meta-analysis. Environ Health Perspect 120(10):1362-1368. https://doi.org/10.1289/ehp.1104912

de Carvalho JG, de Oliveira RC, Buzalaf MA (2006) Plasma as an indicator of bone fluoride levels in rats chronically exposed to fluoride. $\mathrm{J}$ Appl Oral Sci 14(4):238-241. https://doi.org/10.1590/S167877572006000400005

Dong Y, Wang Y, Wei N, Guan Z (2015a) Expression of muscarinic acetylcholine receptors in the brain of rats with chronic fluorosis. Chinese Journal of Endemiology 34:84-88

Dong YT, Wang Y, Wei N, Zhang QF, Guan ZZ (2015b) Deficit in learning and memory of rats with chronic fluorosis correlates with the decreased expressions of M1 and M3 muscarinic acetylcholine receptors. Arch Toxicol 89(11):1981-1991. https://doi.org/10.1007/ s00204-014-1408-2

Dunipace AJ, Brizendine EJ, Zhang W, Wilson ME, Miller LL, Katz BP, Warrick JM, Stookey GK (1995) Effect of aging on animal response to chronic fluoride exposure. J Dent Res 74(1):358-368. https://doi. org/10.1177/00220345950740011201 
Ekambaram P, Paul V (2001) Calcium preventing locomotor behavioral and dental toxicities of fluoride by decreasing serum fluoride level in rats. Environ Toxicol Pharmacol 9(4):141-146. https://doi.org/10. 1016/S1382-6689(00)00063-6

Ekstrand J, Boreus LO, de Chateau P (1981) No evidence of transfer of fluoride from plasma to breast milk. British Med J (Clinical Research ed) 283(6294):761-762. https://doi.org/10.1136/bmj.283. 6294.761

Ekstrand J, Ziegler EE, Nelson SE, Fomon SJ (1994) Absorption and retention of dietary and supplemental fluoride by infants. Adv Dental Res 8(2):175-180. https://doi.org/10.1177/08959374940080020701

El-lethey H, Kamel M, Shaheed IB (2010) Neurobehavioral toxicity produced by sodium fluoride in drinking water of laboratory rats. J Am Sci 6:54-63

Elliott L (1967) Lack of effect of administration of fluoride on the central nervous system of rats. Acta Pharmacol Toxicol (Copenh) 25(3): 323-328

Gao Q, Liu YJ, Wu CX, Long YG, Guan ZZ (2008) Effects of fluoride on learning and memory and cholinesterase activity in rat brains. Chinese J Endemiology 27:128-130

Gao Q, Liu Y, Guan Z (2009a) Decreased learning and memory ability in rats with fluorosis: increased oxidative stress and reduced cholinesterase activity in the brain. Fluoride 42:277-285

Gao YL, Liu L, Young L, Huan LZ, Jin HH (2009b) Effects of learning and memory of fluoride and the antagonism of selenium in rats. Studies of Trace Elements and Health 26:1-3

Gui CZ, Ran LY, Li JP, Guan ZZ (2010) Changes of learning and memory ability and brain nicotinic receptors of rat offspring with coal burning fluorosis. Neurotoxicol Teratol 32(5):536-541. https://oi.org/ 10.1016/j.ntt.2010.03.010

Hamilton M (1992) Water fluoridation: a risk assessment perspective. J Environ Health 54:27-32

Inkielewicz-Stepniak I, Radomski MW, Wozniak M (2012) Fisetin prevents fluoride- and dexamethasone-induced oxidative damage in osteoblast and hippocampal cells. Food Chem Toxicol 50(3-4): 583-589. https://doi.org/10.1016/j.fct.2011.12.015

Jackson D, Weidmann SM (1958) Fluorine in human bone related to age and the water supply of different regions. J Pathol Bacteriol 76(2): 451-459. https://doi.org/10.1002/path.1700760214

Jiang S, Su J, Yao S, Zhang Y, Cao F, Wang F, Wang H, Li J, Xi S (2014a) Fluoride and arsenic exposure impairs learning and memory and decreases mGluR5 expression in the hippocampus and cortex in rats. PLoS One 9(4):e96041. https://doi.org/10.1371/journal.pone. 0096041

Jiang C, Zhang S, Liu H, Guan Z, Zeng Q, Zhang C, Lei R, Xia T, Wang Z, Yang L, Chen Y, Wu X, Zhang X, Cui Y, Yu L, Wang A (2014b) Low glucose utilization and neurodegenerative changes caused by sodium fluoride exposure in rat's developmental brain. NeuroMolecular Med 16(1):94-105. https://doi.org/10.1007/ s12017-013-8260-Z

Jortner BS (2006) The return of the dark neuron. A histological artifact complicating contemporary neurotoxicologic evaluation. Neurotoxicology 27(4):628-634. https://doi.org/10.1016/j.neuro. 2006.03.002

Kaminsky LS, Mahoney MC, Leach J, Melius J, Miller MJ (1990) Fluoride: benefits and risks of exposure. Critical reviews in oral biology and medicine: an official publication of the American Association of Oral Biologists 1(4):261-281. https://doi.org/10. $1177 / 10454411900010040501$

Lalonde R (2002) The neurobiological basis of spontaneous alternation. Neurosci Biobehav Rev 26(1):91-104. https://doi.org/10.1016/ S0149-7634(01)00041-0

Lee J, Han Y-E, Favorow O, Tommerdahl M, Whitsel B, Lee CJ (2016) Fluoride induces a volume reduction in CA1 hippocampal slices via MAP kinase pathway through volume regulated anion channels. Exper Neurobiol 25(2):72-78. https://doi.org/10.5607/en.2016.25.2.72
Li M, Cui J, Gao YH, Zhang W, Sun LY, Liu XN, Liu Y, Sun DJ (2015) Pathological changes and effect on the learning and memory ability in rats exposed to fluoride and aluminum. Toxicol Res 4(5):13661373. https://doi.org/10.1039/C5TX00050E

Liu YJ, Gao Q, Wu CX, Long YG, Guan ZZ (2009) Modified expression of extracellular signal-regulated protein kinase signal transduction in rat brains and changed capacity of learning and memory of rats with chronic fluorosis. Chinese J Endemiology 28:32-35

Lombarte M, Fina BL, Lupo M, Buzalaf MA, Rigalli A (2013) Physical exercise ameliorates the toxic effect of fluoride on the insulin-glucose system. J Endocrinol 218(1):99-103. https://doi.org/10.1530/ JOE-13-0067

Moore JF, Sharer JD (2017) Methods for quantitative creatinine determination. Curr Protoc Hum Genet 93:A.3O.1-A.3O.7. https://doi.org/ 10.1002/cphg.38

Mullenix PJ, Denbesten PK, Schunior A, Kernan WJ (1995) Neurotoxicity of sodium fluoride in rats. Neurotoxicol Teratol 17(2):169-177. https://doi.org/10.1016/0892-0362(94)00070-T

Niu R, Sun Z, Cheng Z, Li Z, Wang J (2009) Decreased learning ability and low hippocampus glutamate in offspring rats exposed to fluoride and lead. Environ Toxicol Pharmacol 28(2):254-258. https:// doi.org/10.1016/j.etap.2009.04.012

NRC (2006) National Research Council report—fluoride in drinking water: a scientific review of EPA's standards, National Academy Press, Washington. http://cof-cof.ca/2006/03/nrc-report-fluoride-indrinking-water-national-research-council-2006/ [Accessed 11/6/2017]

Walf AA, Frye CA (2007) The use of the elevated plus maze as an assay of anxiety-related behavior in rodents. Nat Protoc 2(2):322-328. https://doi.org/10.1038/nprot.2007.44

NTP (National Toxicology Program) (2015) Neurobehavioral testing specifications. Research Triangle Park: National Toxicology Program. https://ntp.niehs.nih.gov/ntp/test_info/finalntp_ neurospecs090415 508.pdf [accessed 11/6/2017]

NTP (2016) Systematic literature review on the effects of fluoride on learning and memory in animal studies. NTP research report 1. Research Triangle Park: National Toxicology Program. http://ntp. niehs.nih.gov/ntp/ohat/pubs/ntp_rr/01fluoride_508.pdf [accessed $11 / 6 / 2017]$

R Core Team (2016) R: a language and environment for statistical computing. R Foundation for Statistical Computing, Vienna. https:// www.R-project.org/. [accessed 11/6/2017]

Rao HV, Beliles RP, Whitford GM, Turner CH (1995) A physiologically based pharmacokinetic model for fluoride uptake by bone. Regul Toxicol Pharmacol 22(1):30-42. https://doi.org/10.1006/rtph.1995.1065

Rogalska A, Kuter K, Żelazko A, Głogowska-Gruszka A, Swietoxhowska E, Nowak P (2017) Fluoride alteration of $\left[{ }^{3} \mathrm{H}\right]$ glucose uptake in Wistar rat brain and peripheral tissues. Neurotox Res 31(3):436443. https://doi.org/10.1007/s12640-017-9709-x

Rumiantsev GI, Novikov SM, Mel'nikova NN, Levchenko NI, Kozeeva EE (1988) Experimental study of the biological effect of salts of hydrofluosilicic acid. Gig Sanit 11:80-82

Shalini B, Sharma JD (2015) Beneficial effects of Emblica officinalis on fluoride-induced toxicity on brain biochemical indexes and learning-memory in rats. Toxicol Int 22(1):35-39. https://doi.org/ 10.4103/0971-6580.172254

Shashi A, Kumar J (2016) Neuropathological changes in hippocampus in albino rat in fluoride toxicity. Inter J Basic and Appl Med Sci 6:17-25

Shen YW, Taves DR (1974) Fluoride concentrations in the human placenta and maternal and cord blood. Am J Obstet Gynecol 119(2): 205-207. https://doi.org/10.1016/0002-9378(74)90035-0

Shivarajashankara YM, Shivashankara AR, Bhat G, Rao PM, Rao SH (2002) Histological changes in the brain of young fluorideintoxicated rats. Fluoride 35:12-21

Shuhua X, Ziyou L, Ling Y, Fei W, Sun G (2012) A role of fluoride on free radical generation and oxidative stress in BV-2 microglia cells. 
Mediat Inflamm 2012:102954-102958. https://oi.org/10.1155/ 2012/102954

Sutton M, Kiersey R, Farragher L, Long J (2015) Health effects of water fluoridation: an evidence review. Report conducted for Republic of Ireland's Department of Health. http://www.hrb.ie/uploads/tx hrbpublications/Health_Effects_of_Water_Fluoridation.pdf Accessed Nov 62017

Taves DR, Neuman WF (1964) Factors controlling calcification in vitro: fluoride and magnesium. Arch Biochem Biophys 108(3):390-397. https://doi.org/10.1016/0003-9861(64)90418-7

US EPA (2010) Fluoride: exposure and relative source contribution analysis. 820-R-10-015. Washington: U.S. Environmental Protection Agency. Office of Water, Health and Ecological Criteria Division. http://www.epa.gov/dwstandardsregulations/fluoride-riskassessment-and-relative-source-contribution [Accessed July 1 2017]

US EPA (2013) Basic information about fluoride in drinking water: review of fluoride drinking water standard. U.S. Environmental Protection Agency. Washington D.C. http://www2.epa.gov/ dwsixyearreview/review-fluoride-drinking-water-regulation. [Accessed July 12017 ]

Vorhees CV, Williams MT (2006) Morris water maze: procedures for assessing spatial and related forms of learning and memory. Nat Protoc 1(2):848-858. https://doi.org/10.1038/nprot.2006.116

Wang J, Ge Y, Ning H, Wang S (2004) Effects of high fluoride and low iodine on biochemical indexes of the brain and learning-memory of offspring rats. Fluoride 37(3):201-208

Wei N, Dong Y, Wang Y, Guan Z (2014) Effects of chronic fluorosis on neurobehavioral development in offspring of rats and antagonistic effect of vitamin E. Chinese J Endemiol 33:125-128

Whitford GM (1996) The metabolism and toxicity of fluoride, 2nd rev. Ed. monographs in oral science Vol. 16. Karger, New York

Whitford GM (1999) Fluoride metabolism and excretion in children. J Public Health Dent 59(4):224-228. https://doi.org/10.1111/j.17527325.1999.tb03273.x

Whitford GM, Whitford JL, Hobbs SH (2009) Appetitive-based learning in rats: lack of effect of chronic exposure to fluoride. Neurotoxicol Teratol 31(4):210-215. https://doi.org/10.1016/j.ntt.2009.02.003
Wu C, Gu X, Ge Y, Zhang J, Wang J (2006) Effects of high fluoride and arsenic on brain biochemical indexes and learning-memory in rats. Fluoride 39:274-279

Wu N, Zhao A, Gao W, Li X (2008) Behavioral teratology in rats exposed to fluoride. Fluoride 41:129-133

Yan L, Liu S, Wang C, Wang F, Song Y, Yan N, Xi S, Liu Z, Sun G (2013) JNK and NADPH oxidase involved in fluoride-induced oxidative stress in BV-2 microglia cells. Mediat Inflamm 2013:1-10. https:// doi.org/10.1155/2013/895975

Yan N, Liu Y, Liu S, Cao S, Wang F, Wang Z, Xi S (2016) Fluorideinduced neuron apoptosis and expressions of inflammatory factors by activating microglia in rat brain. Mol Neurobiol 53(7):4449 4460. https://doi.org/10.1007/s12035-015-9380-2

Zhang M, Wang A, Xia T, He P (2008) Effects of fluoride on DNA damage, S-phase cell-cycle arrest and the expression of NF-kB in primary cultured rat hippocampal neurons. Tox Lett 179(1):1-5. https://doi.org/10.1016/j.toxlet.2008.03.002

Teng Y, Zhang J, Zhang Z, Feng J (2017) The effect of chronic fluorosis on calcium ions and CaMKIIa, and c-fos expression in the rat hippocampus. Biol Trace Elem Res. https://oi.org/10.1007/s12011017-1098-8

Zhu YP, Xi SH, Li MY, Ding TT, Liu N, Cao FY, Zeng Y, Liu XJ, Tong JW, Jiang SF (2017) Fluoride and arsenic exposure affects spatial memory and activates the ERK/CREB signaling pathway in offspring rats. Neurotoxicology 59:56-64. https://doi.org/10.1016/j. neuro.2017.01.006

Zipkin I, Mcclure FJ, Leone NC, Lee WA (1958) Fluoride deposition in human bones after prolonger ingestion of fluoride in drinking water. Public Health Rep 73(8):732-740. https://doi.org/10.2307/4590229

Zipkin I, McClure FJ (1952) Deposition of fluorine in the bones and teeth of the growing rat. J Nutr 47(4):611-620

Zsombok A, Tóth Z, Gallyas F (2005) Basophilia, acidophilia and argyrophilia of "dark" (compacted) neurons during their formation, recovery or death in an otherwise undamaged environment. J Neurosci Methods 142(1):145-152. https://doi.org/10.1016/j. jneumeth.2004.08.005 